\title{
The Effect of Conference Calls on Analysts' Forecasts - German Evidence
}

\author{
Moritz Bassemir, Zoltan Novotny-Farkas, Julian Pachta*
}

This Draft: November 2011

European Accounting Review, forthcoming

\footnotetext{
*Dipl.-Kfm. Moritz Bassemir, Mag. Zoltan Novotny-Farkas, Dipl.-Kfm. Julian Pachta, Chair of Accounting and Auditing, Prof. Dr. Günther Gebhardt, Goethe-University Frankfurt/Main. Address: Grüneburgplatz 1, 60323 Frankfurt/Main. Corresponding E-Mail: mbassemir@wiwi.uni-frankfurt.de. We thank Salvador Carmona (the editor), Felix Fischer, Günther Gebhardt, Martin Glaum (discussant at the VHB Annual Conference 2010), Monika Hommel, Michael Raab, Michael Scholz, Joao Toniato, two anonymous referees, workshop participants at the EAA Annual Congress 2010, the VHB Annual Conference 2010, and two anonymous reviewers for the VHB Annual Conference 2010 for their valuable comments. Moritz Bassemir is grateful to the Schmalenbach Gesellschaft für Betriebswirtschaft for providing financial support to travel to the EAA Annual Congress 2010. Zoltan Novotny-Farkas gratefully acknowledges the financial contribution of the European Commission Research Training Network INTACCT (Contract MRTN-CT-2006-035850). Part of the data was collected during a research visit to the INTACCT partner institution Lancaster University.
} 


\begin{abstract}
This study examines whether conference calls provide additional information to analysts. For a large sample of conference calls, hosted by German firms between 2004 and 2007, our results show that conference calls improve analysts' ability to forecast future earnings accurately. This suggests that additional information is released during conference calls. The reduction in forecast error is economically significant and larger in magnitude when compared to results for the US (Bowen et al., 2002). These findings are consistent with the notion that committing to additional disclosures is likely to yield greater effects in a less stringent disclosure system (Verrecchia, 2001). Since the majority of our sample firms conduct conference calls as closed calls, the evidence of this paper suggests that conference calls may contribute to an information gap between call participants and non-invited parties. Our findings should be of substantial interest to European regulators seeking to level the informational playing field for all investors.
\end{abstract}

\title{
JEL-Classifications: G14; G15; G18; K22.
}

Keywords: analyst conferences; conference calls; disclosure regulation; financial analysts; forecast accuracy; information environment. 


\section{Introduction}

In this paper we investigate whether conference calls provide additional information to the analyst community that cannot be accessed via other types of disclosure. The complementary view suggests that analysts infer new material information during conference calls. This can occur, for example, during management presentations or interactions with management and fellow analysts. Alternatively, conference calls may merely serve as just another method of distributing the same information that was (previously) released through other information channels, e.g., earnings announcements. This view presumes that conference calls are a substitute for disclosing information in other ways. Our study provides evidence that conference calls convey extra information to analysts, beyond that contained in corresponding earnings announcements, lending support to a complementary informational role of conference calls.

So far, research on this question has exclusively focused on the US setting. The effects of firm disclosure on analysts' forecasts, however, are likely to depend on the institutional framework (e.g., Basu et al., 1998; Chang et al., 2000; Hope, 2003b). Therefore, the results from the US may not generalise to other forecasting environments. The German forecasting environment has been perceived to be very different from both that of the US and that of the UK (Capstaff et al., 1998; Bolliger, 2004). For instance, prior studies show that German analysts' forecasting accuracy is relatively poor compared to that of analysts from Anglo-Saxon countries (Chang et al., 2000; Ang and Ciccone, 2001; Capstaff et al., 2001; Clement et al., 2003; Hope, 2003b; Hope, 2003a; Hope, 2004), their recommendations add less value than the recommendations of US analysts (Jegadeesh and Kim, 2006), quarterly forecasts are less common, a smaller number of public firms are covered by analysts (Daske and Wiesenbach, 2005), German analysts have less experience than their US counterparts (Clement et al., 2003) and German brokerage houses are smaller (Naujoks et al., 2009). The differences in the forecasting environments have been attributed to the stronger insider-orientation of the German disclosure system (Capstaff et al., 1998; Chang et al., 2000; Ang and Ciccone, 2001; Hope, 2004). Given the environmental differences, we see a clear motivation to focus our research question on the German setting. While there are conspicuous differences between the German and the US and UK settings, the former is, however, far from being unique in the European context. France, Italy, Spain and other countries in Continental Europe are fairly similar in terms of the relative importance of equity markets and in their information environments. Thus, although this study only 
examines German data, we believe that our results may extend to companies from other Continental European countries as well.

In Germany, in 2003, the Deutsche Börse Group introduced the obligation, for firms listed in the stock market segment Prime Standard, to host at least one conference call per year (Section 68 of the Exchange Rules for the Frankfurt Stock Exchange). The stronger insider-orientation of the German information environment may influence how these conference calls affect analysts' forecasts. On the one hand, if firms seriously commit themselves to greater transparency, the effects of additional disclosure via conference calls should be more pronounced in such a setting and easier to substantiate empirically than for the richer US or UK disclosure systems (Leuz and Verrecchia, 2000). On the other hand, the mere (mandatory) introduction of conference calls as a disclosure mechanism may only have negligible effects, because firms' incentives to publicly provide additional information may be low. In addition, analysts may not be trained well enough to accurately process firm-provided information.

Our main empirical analysis follows an approach outlined by Bowen et al. (2002): First, we measure forecast error and forecast dispersion before and after earnings announcements. Next, we isolate the effect of conference calls on analysts' forecasts, by comparing the change in forecast error and forecast dispersion between quarters where firms host earnings-related conference calls (conference call quarters) and quarters where firms do not host conference calls (non-conference call quarters) concurrent with the earnings release. For a sample of 3,673 earnings announcements by German firms between 2004 and 2007, we find that forecast error decreases more in quarters where firms host conference calls in conjunction with earnings announcements than in non-conference call quarters. The relatively greater decrease in the forecast error persists over time, indicating a sustained effect of conference calls on the information endowment of analysts. These results still hold after a series of robustness tests are applied. Within-firm tests corroborate the results of our panel regressions.

Overall, our findings suggest that valuable new information is released during conference calls, meaning that conference calls constitute increased disclosure. When contrasted with results for the US, as reported by Bowen et al. (2002), the reduction in forecast error in the German sample is economically larger. This is consistent with the view that commitments to provide additional disclosures are likely to result in larger effects within a disclosure system that is less stringent than the US environment (Verrecchia, 2001, p. 175; Leuz and Wysocki, 2008, p. 29). In a supplemental analysis, we shed light on the question 
of whether all financial analysts benefit equally from the information disseminated during conference calls. Partitioning them into high- and low-ability analysts, based on their prior forecasting ability, reveals that both groups benefit equally from conference calls.

As regards forecast dispersion, we generally fail to detect a statistically significant change during conference call quarters. We find only weak evidence of an increase in forecast dispersion during conference call quarters for the longer measurement period. To gain a deeper insight into the the relation between forecast dispersion and conference calls, we separate forecast dispersion into its underlying theoretical components, uncertainty and information asymmetry, where forecast dispersion is an increasing function of both (Barron, Stanford and $\mathrm{Yu}, 2009)$. We find that overall uncertainty declines after conference calls, while there is a strong increase in information asymmetry among analysts. Thus, the absence of a detectable change in the forecast dispersion after conference calls suggests that the decrease in uncertainty is offset by a proportionate increase in information asymmetry. This finding is consistent with theoretical models (e.g., Kim and Verrecchia, 1994) and empirical evidence (e.g., Barron et al., 2002) demonstrating that anticipated public disclosure can lead to increased information asymmetry, because analysts generate new private information in addition to the public information released during such disclosure events.

Research on the role of conference calls in the flow of information in the German capital market should be of great interest to regulators in Europe. In recent years, the European Commission has undertaken many efforts to assure that relevant information is made available in a timely fashion to all investors in European markets. ${ }^{1}$ Current practice in Germany shows that the vast majority of conference calls are closed calls, i.e., access to conference calls is limited to invited participants. ${ }^{2}$ The evidence presented in this paper suggests that restricting access to conference calls places non-invited market participants

\footnotetext{
${ }^{1}$ For instance, in January 2003 the Directive 2003/6/EC was adopted. Its objective is to preclude the selective disclosure of information. The directive contains three main elements: insider dealing, adhoc publicity and market manipulation. In Germany, Section 15 WpHG (Wertpapierhandelsgesetz, in English: German Security Act) was passed in 1995, requiring listed firms to instantly publish all information that may substantially influence stock prices through ad-hoc press releases. Further, Section 15a WpHG was introduced in the year 2002, establishing that trading activities in a firm's stock by corporate insiders (directors' dealings) must be disclosed.

${ }^{2}$ Following Bushee et al. (2003) and Skinner (2003), we understand "open access conferences" as providing unlimited access to all available information to the universe of capital market participants at the same point in time. For instance, live broadcasts of conference calls calls via the internet (e.g., webcasts) that are open to all interested parties meet these requirements. Drawing a random sample of 80 firms from our full sample of 352 and calling the firms' investor relations agents in February 2010 revealed that $86 \%$ of these firms conduct conference calls as closed calls.
} 
at a (temporary) informational disadvantage. In the US, the SEC addressed the issue of selective disclosure and mandated open access to conference calls with the passing of the Regulation Fair Disclosure (Reg FD) in the year 2000. In contrast, in the most important capital markets of Continental Europe, including those of Germany, France, Italy, and Spain as well as the UK, there is still no requirement for firms to grant open access to conference calls for all interested parties. Therefore, our paper contributes to a regulatory debate aimed at levelling the informational playing field among investors in Europe.

In addition, managers, investors and academics should be interested in learning about the informational role of conference calls. This is particularly true in light of the fact that conference calls have become a frequently-used means of conveying information from management to analysts in Germany in recent years. Managers need to understand how financial analysts process information so as to be able to communicate effectively with them (Bradshaw, 2011, p. 2). Investors need to understand how conference calls affect the information environment of analysts, because they use analysts' forecasts of future earnings in their valuation models or follow analysts' stock recommendations in making their investment decisions. Finally, academics studying the effects of public disclosure on the expected cost of equity capital using analysts' forecasts, should try to gain a deeper understanding of the determinants of analysts' forecast errors (Easton, 2009, p. 335).

This paper extends prior research in the following ways. To the best of our knowledge, we are the first to analyse how conference calls affect analysts' forecasts in a non-US type setting. Examining the informational effect of conference calls in Germany helps provide an understanding of their role in the corporate disclosure process in a less stringent disclosure environment. Prior research has generally only examined differences in the levels of accuracy and bias in earnings forecasts within or across European countries (e.g., Capstaff et al., 1998; Capstaff et al., 2001; Beckers et al., 2004; Bolliger, 2004). Our paper extends this literature by examining how a specific disclosure event can lead to changes in the properties of analysts' forecasts. Moreover, focusing on conference calls allows us to add evidence on the immediate effects of the interaction between management and analysts on the information production of analysts.

The paper proceeds as follows. In the next section we develop the research question underlying the paper and our hypotheses. Section 3 describes the research framework and section 4 reports the sample selection procedure. The results of our main empirical analysis, examining the effect of conference calls on forecast error and dispersion, are provided in section 5. Section 6 contains supplemental tests analysing the relation between conference 
calls and analysts' information precision, and the question of whether all analysts benefit equally from conference calls, as well as robustness tests for our main analysis. Concluding remarks are presented in the final section.

\section{Research Question and Hypotheses Development}

A stylised model of the analyst information processing around earnings announcements is provided in Figure $1 .^{3}$ The process starts out with an earnings forecast that is based on the information endowment of the analyst prior to the earnings release (Earnings forecast PRE). In the next step, firms announce their earnings numbers via press releases and financial reports on their websites. This usually happens before markets open or in the early hours of a trading day. In addition to the earnings release, some firms host a conference call later that same day (CC quarter). Conference calls typically begin with a management presentation lasting 15-20 minutes, in which managers provide their interpretation of the firm's latest earnings. This section is followed by a 25-40 minute-long question-and-answer session during which analysts can ask the management open questions and try to elicit additional information that is not disclosed elsewhere. Subsequently, the analysts process the information collected during the conference call, including it in their post-call earnings forecasts (Earnings forecast POST).

\section{[Insert Figure 1]}

The focus of this study is to analyse whether these conference calls convey information to analysts beyond that provided by the accompanying earnings releases. If conference calls provide information incremental to that in the earnings announcements, this should be reflected in post- vs. pre-differences in the forecast properties when compared across conference call quarters (CC quarters) and non-conference call quarters (NCC quarters). Alternatively, conference calls may not provide additional information to the analyst community, because they may only contain the same information as is released through other information channels. In fact, a frequently-cited motivation for the use of conference calls is that they serve as a substitute for direct contact with analysts (e.g., Lang, 1998, p. 171). The argument is that conference calls are a more efficient means to communicate information that otherwise would be disclosed, for instance, through numerous individual

\footnotetext{
${ }^{3}$ See also Bradshaw (2009) for a schematic of analyst information processing.
} 
calls. If this is the case, the amount of overall disclosure should be the same for conference call quarters as for non-conference call quarters, only the medium is different. Then, any observed change in analyst forecast properties could not be attributed to conference calls per se. This would rather imply that analysts differ primarily in their information processing.

However, there are several reasons why we expect conference calls to convey new, material information to analysts. ${ }^{4}$ First of all, the fact that analysts participate in conference calls indicates that these calls are likely to provide additional information (Frankel et al., 1999; Bowen et al., 2002). Further, several research papers provide direct evidence of the complementary informational role of conference calls. Barron, Byard and Yu (2009) find that the question-and-answer section of conference calls helps analysts to trigger new private information by facilitating their analysis of firms' financial statement disclosures that are released with earnings announcements. Using conference call audio files, Mayew and Venkatachalam (2011) show that managerial vocal cues convey additional information about firms' fundamentals beyond quantitative earnings information. Matsumoto et al. (2011) show, by analysing transcripts of conference calls, that the presentation and discussion sections of conference calls are incrementally informative. There is also more indirect evidence that conference calls represent important information events. Studies focusing on capital market reactions during conference calls find unusually large return volatility and abnormally high trading volumes (Frankel et al., 1999; Bushee et al., 2003; Bushee et al., 2004). Bowen et al. (2002) show, for the US setting, that conference calls reduce forecast error and forecast dispersion in the period around the call. They conclude that conference calls increase the information available to analysts and thus enhance their ability to forecast earnings accurately.

Moreover, in informal discussions with the authors, German analysts particularly stressed the importance of the open, interactive nature of the question-and-answer section, in which they have the opportunity to uncover information that was not discussed in the earnings release. ${ }^{5}$ They also pointed out that conference calls convey valuable inform-

\footnotetext{
${ }^{4}$ Also, our research design includes several features to ensure that any observable change in forecast properties is primarily attributable to the information released during conference calls and not to differences in the analysts' information processing across conference call quarters and non-conference call quarters (see section 3).

${ }^{5}$ There is evidence that (1) managers discriminate among analysts by allowing them to ask questions conditional on how favourably the analyst views the firm (Mayew, 2008) and (2) managers withhold information by not answering analysts' questions (Hollander et al., 2010). However, a manager's unwillingness to disclose is also likely to serve as an informative signal to analysts.
} 
ation beyond the earnings numbers, for instance, through managerial body language or linguistic style. In addition, evidence from a limited sample of conference call transcripts suggests that German firms disclose specific information during conference calls that is not contained in earnings announcements.

Forecast error and forecast dispersion may be affected by public or private information (Byard and Shaw, 2003). In formulating our predictions, we rely on an analytical framework outlined by Barron et al. (1998), hereafter BKLS. They derive how the precision (or quality) of analysts' public and private information is transformed into earnings forecasts. In the BKLS model each analyst possesses public information that is common to all analysts and private information that is idiosyncratic. If additional information is released during conference calls, the precision of the public information available to analysts should increase. Theoretical models and empirical studies demonstrate that public disclosure can play a complementary role around the brief window of an anticipated disclosure event (e.g., Harris and Raviv, 1993; Kim and Verrecchia, 1994; Kim and Verrecchia, 1997; Barron et al., 2002; Barron et al., 2005). ${ }^{6}$ In other words, these studies indicate that analysts also develop new private information in conjunction with a conference call. Consistent with this view, Mayew (2008), p. 629, notes: "If analyst questions are conditioned on the asking analyst's existing unique private information, the public answer, while heard by all analysts, can yield uniquely private information for the analyst asking the question relative to other analysts."

An increase in the precision of public and/or private information reduces analysts' uncertainty about future earnings and should therefore lead to a decrease in the error in the mean forecast. It is important to note, however, that in the BKLS model the effect of a greater precision of public information on the forecast error only holds if the public information is more precise than private information. Hence, whether the error in the mean forecast increases or decreases following an increase in the precision of public information depends on the relative preciseness of public and private information. Given the availability of numerous (mandatory) public disclosure channels such as annual reports, quarterly reports, press releases, etc., we argue that, on average, public information is more

\footnotetext{
${ }^{6}$ Increased public disclosure may also substitute for analysts' private information because public information mitigates the gains from private information (e.g., Kim and Verrecchia, 1991), i.e., conference calls may reduce analysts' incentive to acquire private information (substitutional effect). However, the substitution effect typically occurs when firms make a long-run commitment to greater public disclosure, while the complementary effect is more likely a response to anticipated public disclosure events such as conference calls (Verrecchia, 2001, p. 172).
} 
precise than private information (Bowen et al., 2002, p. 314). ${ }^{7}$ Therefore, if conference calls increase the precision of public and/or private information, we predict that conference calls will be associated with a decrease in the forecast error:

Hypothesis 1: The forecast error of analysts decreases relatively more for quarters in which firms host conference calls than for non-conference call quarters.

Regarding the effect of conference calls on forecast dispersion, predictions are less straightforward. In the BKLS framework increased precision of public information reduces analysts' forecast dispersion, when private information is held constant. However, an increase in the precision of private information leads to a greater divergence of beliefs among analysts, i.e., higher information asymmetry. This can lead to an increase in forecast dispersion. Thus, the overall effect of conference calls on analysts' forecast dispersion depends on the relative increase in public and private information. Since the overall relation between conference calls and forecast dispersion remains unclear ex ante, we test the following non-directional hypothesis (stated in the null form):

Hypothesis 2: Forecast dispersion is unaffected during conference call quarters.

\section{Research Design}

\subsection{Development of Dependent Variables}

Following an approach outlined by Bowen et al. (2002), we first measure changes in forecast error $(\triangle \mathrm{ERROR})$ and dispersion $(\Delta \mathrm{DISP})$ for each earnings announcement date. We use changes in forecast error and dispersion, in order to isolate the effect of the information released during the time period over which the changes are measured. Employing a changes (rather than a levels) specification also mitigates the effect of cross-sectional differences in firms' information environments (Bowen et al., 2002, p. 297; Irani, 2004, p. 18). As a second step, we compare $\triangle \mathrm{ERROR}$ and $\triangle \mathrm{DISP}$ across conference call and non-conference

\footnotetext{
${ }^{7}$ In the BKLS framework private information is by definition uncorrelated. Since it is unlikely that all the information released by managers in private conversations with analysts is unique, much of this information is most likely considered as public information in the BKLS framework (Bowen et al., 2002, p. 315).
} 
call quarters to capture the effect of conference calls on the information environment of the analysts. We follow prior research on the German stock market and use annual earnings forecasts in our empirical analysis, because quarterly forecasts are not commonly available. As a result, we examine how conference calls concurrent with the prior year's annual earnings announcement (EA-Q4 $\left.4_{\mathrm{t}-1}\right)$ and subsequent earnings announcements in the first $\left(\mathrm{EA}-\mathrm{Q} 1_{\mathrm{t}}\right)$, second $\left(\mathrm{EA}-\mathrm{Q} 2_{\mathrm{t}}\right)$ and third $\left(\mathrm{EA}-\mathrm{Q} 3_{\mathrm{t}}\right)$ quarters of the current year affect analysts' ability to forecast the annual earnings of the current year (EA-Q4 $4_{t}$ ) (see Figure 2).

Forecast error (ERROR) is defined as the absolute difference between the mean of forecasted earnings per share and actual earnings per share. ${ }^{8}$ Dispersion (DISP) is defined as the standard deviation of individual analysts' forecasts. We measure ERROR and DISP at two different points in time: before (PRE) and after (POST) a quarterly earnings announcement. We scale these measures by the stock price to control for differences in price-earnings levels across firms:

$$
\begin{gathered}
\Delta \mathrm{ERROR}=\frac{\left|\mathrm{ERROR}_{\mathrm{POST}}\right|-\left|\mathrm{ERROR}_{\mathrm{PRE}}\right|}{\text { share price at PRE horizon date }} \\
\Delta \mathrm{DISP}=\frac{\text { DISP }_{\mathrm{POST}}-\mathrm{DISP}_{\mathrm{PRE}}}{\text { share price at PRE horizon date }}
\end{gathered}
$$

A negative value for $\triangle E R R O R$ implies a decrease in forecast error over the measurement period and, thus, is associated with increased forecast accuracy and vice versa. Similarly, a negative value for $\triangle$ DISP indicates a decrease in forecast dispersion over the measurement period and vice versa.

As Figure 2 depicts, we set the PRE horizon date four days before the earnings announcement date of a given quarter. To reduce the probability of confounding events, we choose a considerably shorter event window than Bowen et al. (2002), who set the PRE horizon date as the beginning of the quarter. ${ }^{9}$ Our post-measure POST1 ends 20 days after the earnings announcement, which gives analysts 20 days to revise their forecasts.

\footnotetext{
${ }^{8} \mathrm{We}$ do not use the I/B/E/S consensus forecast, because we place additional restrictions on the calculation of the forecast error; these are outlined in Table 1 in Section 4.

${ }^{9}$ For our sample ( $\mathrm{N}=2,538$ earnings announcements) the average time period between the beginning of the quarter and EA-Q4 $4_{\mathrm{t}-1}$ (i.e., the announcement of the $\mathrm{Q} 4_{\mathrm{t}-1}$ earnings) is 79 days, for EA-Q1 $1_{\mathrm{t}}$ : 39 days, EA-Q2 $2_{\mathrm{t}}$ : 38 days, and EA-Q3 $3_{\mathrm{t}}$ : 39 days.
} 
Changes in forecast accuracy and dispersion between PRE and POST1 are denoted as $\triangle$ ERROR1 and $\triangle \mathrm{DISP} 1$, respectively. A quarter is considered as a conference call quarter if a firm hosts a conference call within a nine-day time period, beginning three days before and ending five days after the announcement of the prior quarter's earnings $(-3 ;+5)$. We choose this narrow time window to ensure that the conference call is associated with an earnings release. By focusing only on conference calls held in conjunction with earnings announcements, we reduce the possibility that the decision to host a conference call is endogenously determined (Bowen et al., 2002, p. 296). We classify quarters where firms do not host a conference call during the nine-day window as non-conference call quarters. The use of non-conference call firms also controls for a general increase in the disclosure quality of German firms in recent years, as documented by Glaum et al. (2011).

[Insert Figure 2]

In addition, we measure forecast error and dispersion at a later point in time (denoted POST2). This grants analysts an additional 30 days to adjust their forecasts after the earnings release (in total 50 days). ${ }^{10}$ Extending the measurement period allows us to examine whether conference calls have a long-term effect on analysts' forecasts. If nonconference call firms "catch up" with conference call firms by providing relevant information through other disclosure channels after the POST1 horizon date but before POST2, the effect of conference calls may only be temporary. If this is the case, should observe similar changes in forecast accuracy ( $\triangle$ ERROR2) and dispersion $(\Delta$ DISP2) for conference call and non-conference call firms in the POST2 horizon. For each of the measurement dates (PRE, POST1 and POST2), we use the most recent outstanding forecast from each individual analyst to compute the mean forecast. To reduce the potential effect of stale forecasts, we only include those issued within a 90-day window before the measurement date. We then match each analyst's pre- and post-conference call forecasts and retain only those made by analysts with forecasts at all three horizon dates.

\subsection{Panel Regression Analysis}

To test the effect of conference calls on the properties of analysts' forecasts, we adopt and extend a model by Bowen et al. (2002). In addition to using changes in forecast measures

\footnotetext{
${ }^{10}$ Bowen et al. (2002) set the POST2 time horizon at the earnings release date of the next interim earnings. Our research design ensures that information coming along with the next interim earnings release is not included in $\triangle$ ERROR2. Also, a constant time frame of an additional 30 days gives all firms the same amount of time to "catch up".
} 
rather than levels, we include several control variables in the model to control for potential differences in firms' information environments. Specifically, we run the following ordinary least square (OLS) regressions:

$$
\begin{aligned}
\Delta \operatorname{ERROR} 1(2)_{\mathrm{i}, \mathrm{q}, \mathrm{t}}=\beta_{0}+ & \beta_{1} \mathrm{CC}_{\mathrm{i}, \mathrm{q}, \mathrm{t}}+\beta_{2} \mathrm{SIZE}_{\mathrm{i}, \mathrm{q}, \mathrm{t}}+\beta_{3} \operatorname{SURP}_{\mathrm{i}, \mathrm{q}, \mathrm{t}}+\beta_{4} \Delta \operatorname{AGE} 1(2)_{\mathrm{i}, \mathrm{q}, \mathrm{t}} \\
+ & \beta_{5} \operatorname{ERROR}_{\mathrm{PRE}, \mathrm{i}, \mathrm{q}, \mathrm{t}}+\beta_{6} \mathrm{NO}_{\mathrm{i}, \mathrm{q}, \mathrm{t}}+\sum \beta_{\mathrm{j}} \text { Fixed Effects }+\epsilon, \\
\Delta \operatorname{DISP} 1(2)_{\mathrm{i}, \mathrm{q}, \mathrm{t}}=\beta_{0}+ & \beta_{1} \mathrm{CC}_{\mathrm{i}, \mathrm{q}, \mathrm{t}}+\beta_{2} \mathrm{SIZE}_{\mathrm{i}, \mathrm{q}, \mathrm{t}}+\beta_{3} \mathrm{SURP}_{\mathrm{i}, \mathrm{q}, \mathrm{t}}+\beta_{4} \Delta \mathrm{AGE} 1(2)_{\mathrm{i}, \mathrm{q}, \mathrm{t}} \\
& +\beta_{5} \operatorname{DISP}_{\mathrm{PRE}, \mathrm{i}, \mathrm{q}, \mathrm{t}}+\beta_{6} \mathrm{NO}_{\mathrm{i}, \mathrm{q}, \mathrm{t}}+\sum \beta_{\mathrm{j}} \text { Fixed Effects }+\epsilon .
\end{aligned}
$$

where:

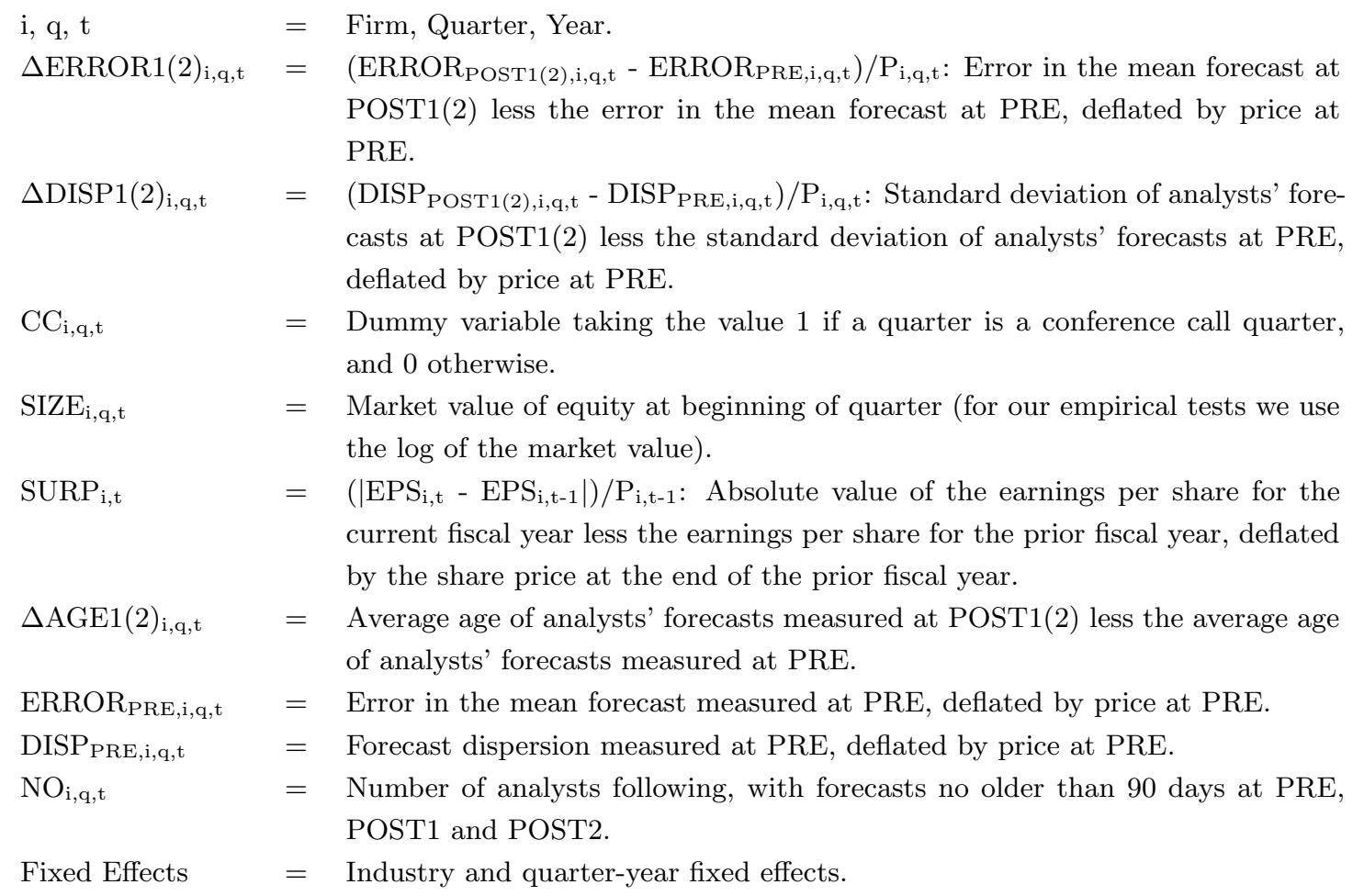

Previous literature has shown that size affects the level of information available about a firm (e.g., Lang and Lundholm, 1996). As a proxy for SIZE, we use the firm's market value of equity. ${ }^{11}$ Furthermore, we include an earnings surprise variable (SURP), defined

\footnotetext{
${ }^{11}$ Results are qualitatively similar if we choose total assets as a proxy for SIZE.
} 
as the change in earnings relative to the prior year, to control for the analysts' difficulty in forecasting earnings (Lang and Lundholm, 1996; Bowen et al., 2002). In addition, we use the difference in the age of the mean forecasts (AGE) at the PRE and POST measurement dates to control for staleness in the forecasts, which would potentially increase the levels of forecast error and forecast dispersion (e.g., Brown, 2001). The variable AGE also captures the tendency of analysts to revise their forecasts after conference calls.

Further, we incorporate the pre-levels of forecast error (ERROR PRE $_{\text {) }}$ and dispersion (DISP PRE) into our regressions. The initial levels are likely to be affected by the richness of a firm's information environment. Firms with lower pre-levels of forecast error and dispersion also have less room to improve after a conference call. We also add the number of analysts following (NO) to our regression model. NO serves as a proxy for the competition among analysts, which can produce incentives to revise annual forecasts after interim earnings announcements (Stickel, 1989, p. 279). In order to eliminate the influence of the industrial sector on analysts' forecasts (e.g., Brown, 1997; Capstaff et al., 2001), we include industry fixed effects. This allows us to capture any unobserved, time-invariant heterogeneity across industries. Finally, we introduce quarter-year fixed effects to account for the quarterly structure of our panel data set and to control for time trends (Christensen et al., 2011).

The incremental effect of conference calls may also depend on a firm's accounting regime, because earnings numbers prepared under international accounting standards are arguably more informative than those prepared under local standards. However, we do not control for the presence of international accounting standards. The reason for this is that our sample firms were required to apply either IFRS or US-GAAP in 2005 and many firms had already made the switch by the start of our investigation period in 2004 .

\subsection{Within-Firm Analysis}

In addition to our panel regression analysis, we employ within-firm tests which control for (unobserved) firm-specific factors that are constant over time (Bowen et al., 2002, p. 298). Specifically, we compare - for the same firm - changes in forecast error and dispersion during conference call quarters with changes in the forecast measures during non-conference call quarters one year earlier. These tests allow us to analyse how analysts' forecasts are affected if a firm (re-)commences hosting conference calls in a given quarter. 
For each firm with data available, we compute the following relations:

$$
\begin{gathered}
\Delta \Delta \operatorname{ERROR} 1(2)_{\mathrm{i}, \mathrm{q}, \mathrm{t}}=\Delta \operatorname{ERROR} 1(2)_{\mathrm{i}, \mathrm{q}, \mathrm{t}}^{\mathrm{CC}}-\Delta \operatorname{ERROR} 1(2)_{\mathrm{i}, \mathrm{q}, \mathrm{t}-1}^{\mathrm{NCC}} \\
\Delta \Delta \operatorname{DISP} 1(2)_{\mathrm{i}, \mathrm{q}, \mathrm{t}}=\Delta \operatorname{DISP} 1(2)_{\mathrm{i}, \mathrm{q}, \mathrm{t}}^{\mathrm{CC}}-\Delta \operatorname{DISP} 1(2)_{\mathrm{i}, \mathrm{q}, \mathrm{t}-1}^{\mathrm{NCC}}
\end{gathered}
$$

where:

$\mathrm{CC}=$ Conference call quarter.

$\mathrm{NCC}=$ Non-conference call quarter.

For definitions of $\Delta$ ERROR1(2) and $\Delta$ DISP1(2), see Figure 2.

We expect the change in forecast error to be higher in conference-call quarters than in non-conference call quarters, which implies a negative value for $\Delta \Delta \operatorname{ERROR} 1(2)$. For reasons discussed in section 2, we offer no directional hypothesis for $\Delta \Delta \operatorname{DISP1}(2)$.

\section{Sample Selection and Data Collection}

Our sample selection procedure starts out with 352 German firms listed in the Prime Standard Index of the Deutsche Börse Group (as of March 2009). The Prime Standard is the stock market segment with the strongest transparency requirements in Germany. Notably, all firms included in the Prime Standard must report their earnings on a quarterly basis and are obliged to conduct at least one conference call per year. Additionally, they must provide a financial calendar on their website, with the dates of all important corporate events such as earnings releases and conference calls.

As summarised in Table 1, the data collection process involves the following steps: First, we identify the earnings release dates for all 352 firms between 2004 and 2007. There are several databases (e.g., investor-facts.de, dvfa.de, earnings.com) covering the earnings release dates of German firms. However, cross-checks with firms' websites reveal that these data are far from being complete and sometimes even erroneous. Therefore, we gather all earnings release dates by manually checking the firms' financial calendars on their websites and their financial reports. This search yields a total of 4,449 earnings release dates. This is less than the theoretical maximum amount of 5,632 earnings releases because some firms entered the Prime Standard after 2004. Secondly, we also manually check whether a conference call is hosted within a nine-day window $(-3 ;+5)$ surrounding an identified earnings announcement. Current practice indicates that the conference call date coincides with the date the earnings release is published. In our analysis we consider 
all earnings-related conference calls, regardless of whether they are held physically or as a telephone/webcast conference. ${ }^{12}$ This procedure yields 2,099 conference call quarters and 2,350 non-conference call quarters.

\section{[Insert Table 1]}

Next, we merge our initial sample with forecast data provided by I/B/E/S. Since not all of our sample firms are covered by I/B/E/S analysts, we lose 776 observations. This results in a preliminary sample of 3,673 earnings announcements comprising 1,875 conference call quarters and 1,798 non-conference call quarters, with corresponding forecast data from I/B/E/S. Finally, we place additional restrictions on the combined sample when conducting our tests (see Table 1). We delete all observations with no forecast revision within a 90-day window before each measurement date to ensure that only analysts who actively follow the firm are included in the computation of forecast error and dispersion. The 90-day maximum age restriction does not necessarily imply that forecasts need to be revised between the PRE and the POST1 or POST2 time horizons. Therefore, it is also possible that some forecasts in the POST measures are actually made prior to an earnings release. No revision would indicate that the earnings release and/or the conference call did not provide additional information prompting the analyst to adjust annual forecasts. ${ }^{13}$ Furthermore, we discard observations for which the prior year's actual EPS value is not available because we also include in our regression model the change in earnings relative to the prior year as a proxy for the analyst's difficulty in forecasting earnings (see section 3.2). We also delete observations for the POST1(2)-samples for which the time period between subsequent earnings announcements is less than 24 (54) days, so as to avoid overlapping measurement periods. ${ }^{14}$

In order to calculate forecast dispersion, we require at least two forecasts to be currently outstanding. For the empirical tests, we also delete the top and bottom $1 \%$ of all

\footnotetext{
${ }^{12}$ In Germany, conference calls related to the annual earnings announcement are usually held physically, while conference calls in conjunction with quarterly earnings releases are conducted as telephone and/or webcast access conferences. This information was inferred during several informal conversations between the authors and investor relations officers from Prime Standard firms.

${ }^{13}$ However, we control for the age of forecasts in our multivariate regressions. Also, in sensitivity tests we only include observations for which forecasts are revised within the 20 days following an earnings announcement.

${ }^{14}$ For our sample ( $\mathrm{N}=2,538$ earnings announcements), the average time period between subsequent earnings announcements for EA-Q4 $4_{\mathrm{t}-1} \rightarrow \mathrm{EA}-\mathrm{Q} 1_{\mathrm{t}}$ is 50 days, for EA-Q1 $\rightarrow$ EA-Q2 $2_{\mathrm{t}}: 91$ days, EA-Q2 $\rightarrow$ EA$\mathrm{Q} 3_{\mathrm{t}}$ : 92 days, and $\mathrm{EA}-\mathrm{Q} 3_{\mathrm{t}} \rightarrow \mathrm{EA}-\mathrm{Q} 4_{\mathrm{t}}: 130$ days.
} 
dependent variables. Our final $\Delta$ ERROR1(2)-sample comprises 2,338 $(2,023)$ observations and our final $\Delta$ DISP1(2)-sample comprises $1,848(1,580)$ observations.

\section{Main Empirical Analyses}

\subsection{Descriptive Statistics and Results of Univariate Tests}

Figure 3 plots the frequency of individual forecasts revisions around earnings announcements for conference call quarters and non-conference call quarters separately.

[Insert Figure 3]

It is apparent that revisions of individual analysts' forecasts are highly concentrated in the period starting with the earnings announcement date (day 0) and ending two days after the earnings announcement (day +2$)$. However, the percentage of forecast revisions is higher for conference call quarters (19\%) than for non-conference call quarters (13\%). This indicates that analysts are more likely to revise their forecasts when a firm hosts a conference call in conjunction with the earnings announcement.

Table 2 summarises the descriptive statistics for the dependent, explanatory and control variables for the combined sample of treatment and control group. Decreases in forecast error scaled by share price occur both in the shorter $(-4 ;+20$ days $)$ window $(\Delta$ ERROR 1$)$ and in the longer $(-4 ;+50$ days) window $(\Delta$ ERROR2). They are significantly different from zero according to both t-tests and Wilcoxon signed-rank tests. Changes in forecast dispersion $(\Delta \mathrm{DISP} 1(2))$ generally exhibit a positive sign, except for the median in the POST2 window, indicating that forecast dispersion tends to increase. However, as a percentage of share price, changes in forecast dispersion appear to be smaller than changes in forecast error and are not significantly different from zero. For the $\Delta$ ERROR1$(\Delta$ DISP1-)sample, approximately $60 \%(68 \%)$ of all earnings announcements are in conjunction with conference calls.

The mean (median) market value of equity, our proxy for firm size (SIZE), is 743 (566) million EUR for the pooled sample. The negative sign for $\triangle \mathrm{AGE1}$, which is the average age of earnings forecasts at the POSTl horizon less the average age of earnings forecasts at the PRE horizon, suggests that forecasts at the PRE horizon date are older than at the POST1 horizon date. Thus, on average, analysts revise their forecasts subsequent to an earnings announcement date. The positive value of $\triangle$ AGE2 indicates that forecasts are 
more recent at the PRE time horizon than at the POST2 time horizon. This leads to the conclusion that only some analysts revise their forecasts (again) in the "catch up" period.

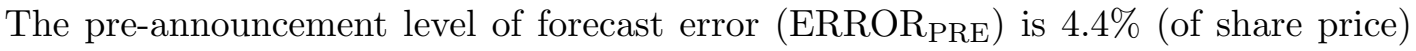
for our combined sample and, as such, larger than for US firms. ${ }^{15}$ This is in line with prior research demonstrating that the forecasting accuracy of German analysts is relatively poor compared to that of analysts from Anglo-Saxon countries (e.g., Clement et al., 2003). The mean (median) number of active analysts following (NO) is around 7 (5).

[Insert Table 2]

Univariate tests comparing changes in forecast measures across conference call quarters and non-conference call quarters are presented in Table 3. Consistent with hypothesis 1 , the decrease in $\triangle$ ERROR1 is significantly higher in quarters where firms host conference calls concurrent with earnings announcements than it is in non-conference call quarters, as indicated by both the parametric and non-parametric tests. $\triangle$ ERROR2 is significantly lower for conference call quarters, indicating that the reduction in the forecast error also persists through the longer POST2 period. As a percentage of the pre-announcement level of forecast error (ERROR $\mathrm{PRE}_{\mathrm{P}}$ ), the decreases in forecast error for conference call quarters and non-conference call quarters have means (medians) of $8.68 \%(7.27 \%)$ and $3.82 \%(0 \%)$ in the POST1 period, respectively. The absolute decrease in forecast error scaled by price, $0.3 \%$, remains large when contrasted with the result for the US of $0.09 \%$, as documented by Bowen et al. (2002). These numbers suggest that the stronger reduction in the forecast error for conference call firms is also significant in economic terms.

\section{[Insert Table 3]}

Forecast dispersion goes up in the mean but declines in the median after conference calls. We fail to find significant differences for the change in forecast dispersion between conference call quarters and non-conference call quarters. As regards our control variables capturing firms' information environment, Table 3 shows that larger firms (SIZE) and firms with more analysts following them (NO) host conference calls more frequently. Further, the change in the average age of the forecasts ( $\triangle \mathrm{AGE} 1$ and $\triangle \mathrm{AGE2}$ ) is significantly greater

\footnotetext{
${ }^{15}$ For the combined sample, Bowen et al. (2002), p. 300, report an average initial level of forecast error of $0.4 \%$ (of share price). It should be noted that the larger initial level of forecast error for our German sample may also be partly attributable to the use of annual earnings forecasts (which are more difficult to predict due to the longer forecast horizon), while the study of Bowen et al. (2002) for the US setting is based on quarterly earnings forecasts. However, for our German sample, the initial forecast error one-quarter ahead (at EA-Q3 $3_{\mathrm{t}}$ ) of the forecasted annual earnings (EA-Q4 $4_{\mathrm{t}}$ ) is still $2.6 \%$ (of share price).
} 
in conference call quarters than in non-conference call quarters, confirming that analysts are more likely to revise their forecasts in quarters where firms host a conference call.

\subsection{Results of Multivariate Tests}

Table 4 provides the results of the multivariate analyses. Statistical inferences are based on robust standard errors clustered at the firm level. We test hypothesis 1, positing that the error in the mean forecast decreases relatively more for quarters in which firms host conference calls than for non-conference call quarters, in models 1 and 2. As expected, the coefficients of our main test variable CC are significantly negative (p-values $<0.01$ ) in both models. These results suggest that, both in the shorter $(\triangle$ ERROR1) and in the longer event-window ( $\triangle$ ERROR2), the forecast error decreases significantly more for conference call quarters than for quarters where firms do not host conference calls. Therefore, we conclude that, consistent with hypothesis 1 , conference calls convey additional information beyond the information provided by earnings announcements.

In the short-term, the decrease in forecast error is approximately $0.19 \%$ (of price) greater in conference call quarters than in non-conference call quarters. This difference accounts for $52 \%$ of the interquartile range of $\Delta$ ERROR $1 .{ }^{16}$ For $\Delta$ ERROR2, the difference is about $0.36 \%$ (of price) and $72 \%$ of the interquartile range. These relations indicate that the stronger reduction in forecast error for conference call quarters is also of economic significance. When compared to results for the US setting, as reported by Bowen et al. (2002), revisions in analysts' forecast estimates following conference calls are larger in economic terms for our sample of German firms. ${ }^{17}$ These magnitudes are consistent with the idea that increased disclosure can yield greater effects in a less stringent forecasting environment (Leuz and Verrecchia, 2000; Hail, 2002). The coefficients of the control variables SIZE, $\triangle \mathrm{AGE} 1(2)$ and NO are all highly significant. ${ }^{18}$ ERROR $_{\mathrm{PRE}}$ and SURP have coefficients that are insignificant.

\section{[Insert Table 4]}

\footnotetext{
${ }^{16}$ We obtain this result by dividing the coefficent of $\mathrm{CC}(0.00187)$ by the interquartile range of $\Delta \mathrm{ERROR} 1$ $(0.00015-(-0.00345)=0.00360)$.

${ }^{17}$ Bowen et al. (2002), p. 304, find that the decrease in forecast error is approximately $0.013 \%$ (of price) or $21 \%$ of the interquartile range.

${ }^{18} \mathrm{SIZE}$ and NO are positively correlated, with a coefficient of 0.76 (not tabulated). We assess the presence of multicollinearity by dropping either SIZE or NO from the regression model. The results remain qualitatively similar. Also, VIF statistics do not indicate that multicollinearity presents a severe problem in our regressions.
} 
In a further set of analyses, we use the individual forecast error instead of the error in the mean forecast as the dependent variable. The regression results presented in models 3 and 4 show that the coefficient of our main variable of interest, $\mathrm{CC}$, is significantly negative (p-values $<0.01$ ). This corroborates our previous findings.

We test hypothesis 2, stating that forecast dispersion is unaffected during conference call quarters, in models 5 and 6 . The coefficients of the conference call dummy CC are positive in both models, indicating that forecast dispersion tends to increase during conference call quarters. However, only the coefficient for the POST2 window is statistically significant (p-value: 0.04). Thus, there is weak evidence that forecast dispersion increases relatively more for conference call quarters than for non-conference call quarters for the longer time horizon. None of the control variables enter significantly into our models 5 and 6 (except for SURP).

The lack of statistical significance in model 5 may be due to the skewness of forecast dispersion. To address this issue, we repeat our tests using $\Delta \log$ DISP1, which is defined as the change in dispersion based on the natural log of forecast dispersion levels ( $\log \mathrm{DISP}_{\mathrm{PRE}}$ and $\log$ DISP $\left._{\mathrm{POST}}\right)$. Untabulated results show that the log transformation greatly mitigates the skewness in the level of forecast dispersion. While almost all control variables turn significant (SURP, $\triangle$ AGE1, DISP ${ }_{\mathrm{PRE}}$, and NO), the coefficient estimate for the conference call dummy CC remains insignificant. Thus, using the change in log-transformed dispersion as the dependent variable does not alter our conclusions. ${ }^{19}$

\subsection{Results of Within-Firm Tests}

Table 5 displays the results of the within-firm, across-time analysis. In line with expectations, the sign for $\Delta \Delta$ ERROR1(2) is significantly negative. Thus, consistent with hypothesis 1, forecast error decreases in the mean and median $(\Delta$ ERROR1(2)) significantly more for conference call quarters than for non-conference call quarters. These results indicate that, for firms which eventually (re-)commence hosting conference calls in a given quarter, useful information is released to the analyst community during these conferences.

\section{[Insert Table 5]}

Forecast dispersion $(\Delta \mathrm{DISP} 1(2))$ tends to increase when firms host conference calls. However, we fail to find significant differences between conference call quarters and non-

\footnotetext{
${ }^{19}$ We thank an anonymous referee for bringing this issue to our attention.
} 
conference call quarters. Overall, the results presented in this section confirm the previous findings from the main regression analysis.

\section{Supplemental Analyses}

\subsection{Conference Calls and Information Precision}

In our empirical tests we fail to find significant changes in forecast dispersion during conference call quarters. To further examine the impact of conference calls on the information set of analysts, we use empirical proxies developed by BKLS and decompose forecast dispersion into its underlying theoretical constructs: uncertainty and information asymmetry (Barron, Stanford and Yu, 2009). This analysis allows us to shed light on how conference calls affect the two distinct components of forecast dispersion. In the BKLS framework uncertainty (denoted V) and information asymmetry (denoted 1- $\rho$ ) are defined in terms of observable measures of analysts' forecasts (BKLS, p. 427):

$$
\begin{gathered}
\text { Uncertainty }=\mathrm{V}=\left(1-\frac{1}{\mathrm{NO}}\right) \mathrm{D}+\mathrm{SE} \\
\text { Information asymmetry }=(1-\rho)=1-\frac{\mathrm{SE}-\frac{\mathrm{D}}{\mathrm{NO}}}{\left(1-\frac{1}{\mathrm{NO}}\right) \mathrm{D}+\mathrm{SE}}
\end{gathered}
$$

where:

$\mathrm{V}=$ Overall uncertainty.

$(1-\rho)=$ Information asymmetry.

$\mathrm{D}=$ Forecast dispersion.

$\mathrm{SE}=$ Squared error in the mean forecast.

$\mathrm{NO}=$ Number of analysts following.

We calculate values for $\mathrm{V}$ and $(1-\rho)$ for the PRE and POST1 horizon date. Since we are interested in the effect of conference calls on the information environment of analysts, we test for the signs of the changes in V and (1- $\rho)$ between the PRE and POST1 horizon. In line with prior research, we discuss the median values of the BKLS proxies.

\section{[Insert Table 6]}

The results in Table 6 show that uncertainty significantly declines after each of the four conference call windows. Information asymmetry among analysts generally goes up, indicating that a higher share of private information is contained in analysts' forecasts after 
conference calls. Also, the level of information asymmetry increases as the announcement of the forecasted annual earnings approaches. This suggests that, while analysts rely more on public information for long-term forecasts, they incorporate relatively more private information in their forecasts as the forecast horizon shortens.

As expressed in equation (9), forecast dispersion (D) is an increasing function of both uncertainty and information asymmetry in the BKLS framework (BKLS, p. 426).

$$
\text { Dispersion }=\mathrm{D}=\mathrm{V}(1-\rho)
$$

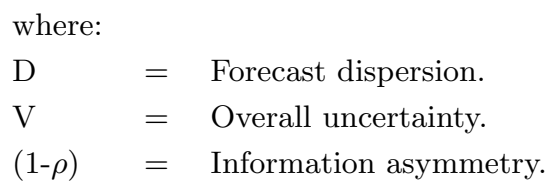

Since we are unable to detect a significant change in forecast dispersion around conference calls, it appears that the effect of reduced uncertainty is offset by an increase in information asymmetry such that forecast dispersion does not change. This finding is consistent with prior theoretical (e.g., Harris and Raviv, 1993; Kim and Verrecchia, 1994; Kim and Verrecchia, 1997) and empirical (e.g., Barron et al., 2002; Barron et al., 2005) research positing that analysts develop new private information upon anticipated public disclosure events which in turn leads to an increase in information asymmetry. However, caution should be exercised when interpreting these results. Naujoks et al. (2009) show that German analysts engage in anti-herding by overemphasizing their private information. This potentially introduces a bias in the BKLS proxy for information asymmetry (Zitzewitz, 2002, p. 6).

\subsection{Do All Analysts Benefit Equally?}

Our univariate and multivariate results suggest that conference calls convey additional information. It is, however, not clear whether all analysts benefit equally from the information provided during conference calls or whether just a subset of analysts drives the observed decrease in the forecast error.

To address this question, we partition analysts into two groups according to their forecasting ability. Following Bowen et al. (2002), we use a relative ranking of analysts' prior forecasting accuracy as a proxy for forecasting ability. First, we calculate mean-adjusted forecast errors by deducting the average forecast error from the individual analysts' fore- 
cast errors for each firm. Next, we compute the average mean-adjusted forecast error at all four PRE horizon dates (EA-Q4 $\left.4_{\mathrm{t}-1}, \mathrm{EA}-\mathrm{Q} 1_{\mathrm{t}}, \mathrm{EA}-\mathrm{Q} 2_{\mathrm{t}}, \mathrm{EA}-\mathrm{Q} 3_{\mathrm{t}}\right)$ in each fiscal year and rank analysts according to their average error. We then calculate percentage rank as the rank value of each analyst divided by the number of analysts ranked which yields scores ranging from zero to one. We consider analysts with a ranking in the prior fiscal year better (equal to or less) than 0.5 as high- (low-) ability analysts for the current year. ${ }^{20}$ Then, we compute for each firm-quarter the average $\Delta$ ERROR1(2) for both the high- and low-ability groups $\left(\Delta \operatorname{ERROR} 1(2)^{\mathrm{HI}}\right.$ and $\Delta$ ERROR1 $\left.(2)^{\mathrm{LO}}\right)$ as well as the average difference between the two groups ( $\left.\Delta \operatorname{ERROR} 1(2)^{\mathrm{HI}-\mathrm{LO}}\right)$ for firms with at least one analyst in each group. If the high- (low-) ability group benefits more from the information provided during conference calls than the low- (high-) ability group then $\Delta$ ERROR1(2) ${ }^{\mathrm{HI}-\mathrm{LO}}$ will be negative (positive).

We also rank analysts based on the forecasting performance of their respective brokerage house. ${ }^{21}$ The ranking follows the same procedure as described above. However, we compute the average mean-adjusted forecast errors at the brokerage house level rather than the individual analyst level.

\section{[Insert Table 7]}

Table 7 provides univariate comparisons of changes in forecast error by analyst type for conference call and non-conference call quarters. Panel A shows significantly larger decreases for $\triangle E R R O R 1^{\mathrm{HI}}$ and $\triangle E R R O R 1^{\mathrm{LO}}$ in conference call than in non-conference call quarters, suggesting that both low- and high-ability analysts benefit from conference calls. For the longer POST2 horizon, $\triangle \mathrm{ERROR} 2^{\mathrm{HI}}$ and $\triangle \mathrm{ERROR} 2^{\mathrm{LO}}$ are significantly smaller (more negative) for conference call quarters than for non-conference call quarters according to the Wilcoxon test, while they are not significantly smaller according to a t-test.

Turning to the question of whether low- and high-ability analysts benefit equally from the information disseminated during conference calls, our variable of interest, $\Delta$ ERROR $1(2)^{\mathrm{HI}-\mathrm{LO}}$, is not significantly different between conference call vs. non-conference call quarters. Thus, we fail to find differences in the informational effect of conference calls for different types

\footnotetext{
${ }^{20}$ If we use alternative cut-off criteria for the ranking of the analysts, such as upper vs. lower quartile, our results remain qualitatively similar.

${ }^{21} \mathrm{I} / \mathrm{B} / \mathrm{E} / \mathrm{S}$ has stopped publishing the names of brokerage houses and analysts. They only assign individual IDs to each brokerage house and analyst, allowing us to track prior performance.
} 
of analysts. When we rank analysts according to their brokerage house affiliations, the results (displayed in Table 7 Panel B) remain qualitatively similar.

We also perform a multivariate test: We regress $\Delta$ ERROR1(2) ${ }^{\mathrm{HI}-\mathrm{LO}}$ on the conference call dummy (CC) and our control variables. ${ }^{22}$ If the low-ability group benefits more from conference calls, we should observe a positive coefficient on the dummy variable CC. However, untabulated regression results show an insignificant coefficient on CC, supporting our inferences from the univariate analysis. ${ }^{23}$

\subsection{Sensitivity Analyses for Main Results}

We perform several sensitivity tests to validate the results of our main empirical analyses. First, to further ascertain that our results are not driven by differences in firms' information environments, we introduce a control variable labelled CCFIRM to our regression models 1 and 2. CCFIRM takes the value 1 for all firm-quarters (conference call and non-conference call) for firms that host more than one conference call per calendar year, and 0 otherwise. ${ }^{24}$ Thus, the coefficient of CCFIRM captures the change in forecast error in non-conference call quarters for firms that host more than one conference call per year (frequent users) relative to the change in forecast error for non-conference call quarters for firms that host just one conference call (mandatory users). For the group of mandatory users, we delete all conference call quarter observations. Consequently, CC now shows the incremental effect of hosting a conference call on analysts' forecasts, for frequent users. Untabulated results show that the coefficient of CC remains significant, while the coefficient of CCFIRM is insignificant in all specifications. Thus, the change in forecast error in non-conference call quarters is not significantly different between frequent and mandatory users. This suggests that the main results of our paper are not driven by differences in the information environments of frequent conference call users relative to those of mandatory users.

Secondly, we address an issue related to our sample restriction of only including forecasts no older than 90 days at each measurement date (see section 4). Under this restriction, analyst forecasts at the POST1(2) time horizons are possibly the same as at the PRE time horizon. It can be argued that these forecasts should be included in the PRE and POST measures, because no revision would indicate that no valuable information is

\footnotetext{
${ }^{22}$ In these regressions, we include the difference between the low- and high-ability groups for $\Delta \mathrm{AGE} 1(2)$

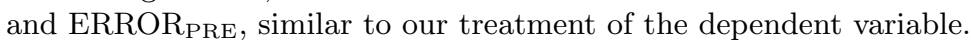

${ }^{23}$ Results are available upon request.

${ }^{24}$ Recall that our sample firms are required by stock market regulations to host at least one conference call per calendar year.
} 
released during earnings announcements or conference calls (Bowen et al., 2002, p. 292, fn. 9). However, as the underlying question of this study is to assess whether conference calls provide additional information not disclosed in earnings releases, it is empirically interesting if actual revisions after an earnings announcement are more accurate when they are accompanied by a conference call. Hence, we exclude observations where no revision has been made within the 20 days following the earnings announcement. Untabulated regression results confirm our primary findings regarding the changes in forecast error and forecast dispersion.

Finally, we repeat the multivariate regressions of models 1 and 2, using the error in the median forecast and the mean of the individual forecast errors, instead of the error in the mean forecast, as the dependent variable. In all specifications our results remain qualitatively unchanged.

\section{Conclusions}

In this paper, we examine whether conference calls convey additional information to analysts beyond that in the accompanying earnings announcements. We consider the German setting, because it generally reflects a forecasting environment that is very different from the more thoroughly studied US or UK markets. The differences may influence how conference calls affect analysts' forecasts. In the Continental European context, however, the German environment is not too different from those of many other countries. Rather, it typifies an information system that is fairly similar to those in France, Italy, Spain and other countries. Therefore, examining conference calls in Germany may help us to understand the informational role of these conference calls in other European countries as well.

Our regression results show that forecast error decreases relatively more in quarters in which firms host conference calls in conjunction with earnings announcements than for non-conference call quarters. The greater decrease in the forecast error persists over time, suggesting a sustained informational effect of conference calls. These findings are robust to a number of control variables and sensitivity tests. Overall, our evidence suggests that conference calls provide new material information to analysts that is not released through other types of disclosure. When compared to the results for the US markets, as reported by Bowen et al. (2002), the observed decrease in forecast error is economically larger. Regarding forecast dispersion, we are unable to find significant changes during conference 
call quarters. To examine the source of changes in forecast dispersion, we use empirical proxies developed by BKLS and separate forecast dispersion into its two theoretical constructs: uncertainty and information asymmetry. The results show that, while uncertainty declines, information asymmetry goes up after conference calls so that forecast dispersion does not change. A supplemental analysis reveals that both low- and high-ability analysts benefit from the information distributed during conference calls. However, neither group of analysts benefits more than the other.

Our results are consistent with the notion that the commitment to increased disclosure should evidence greater effects within less stringent settings than it does in the US disclosure system, where the effects of additional disclosures are likely to be small (Leuz and Verrecchia, 2000). Likewise, our findings indicate that results for the US markets cannot be generalised without empirical testing.

Given that conference calls by German firms are generally restricted, the evidence presented in this paper suggests that conference call participants gain an informational advantage relative to non-participants, which leads to selective disclosure. This may be particularly relevant to European regulators seeking to level the informational playing field in capital markets, but who have yet to introduce legal requirements to conduct conference calls on an open-access basis only.

Since we infer the informational role of conference calls from investigating changes in analysts' forecasts, the evidence of this paper is necessarily indirect. Future research in European markets might further explore the content of conference calls using transcripts. 


\section{References}

Ang, J. S. and Ciccone, S. J. (2001). International differences in analyst forecast properties. Working Paper, Florida State University and University of New Hampshire.

Barron, O. E., Byard, D. and Kim, O. (2002). Changes in Analysts' Information around Earnings Announcements, The Accounting Review 77(4): 821-846.

Barron, O. E., Byard, D. and Yu, Y. (2009). Evidence that Financial Statement Information Beyond that of Earnings Complements Analysts' Private Information. Working Paper, Pennsylvania State University.

Barron, O. E., Harris, D. G. and Stanford, M. (2005). Evidence that Investors Trade on Private Event-Period Information around Earnings Announcements, The Accounting Review 80(2): 403-421.

Barron, O. E., Kim, O., Lim, S. C. and Stevens, D. E. (1998). Using Analysts' Forecasts to Measure Properties of Analysts' Information Environment, The Accounting Review 73(4): 421-433.

Barron, O. E., Stanford, M. H. and Yu, Y. (2009). Further Evidence on the Relation between Analysts' Forecast Dispersion and Stock Returns, Contemporary Accounting Research 26(2): 329-357.

Basu, S., Hwang, L. and Jan, C. (1998). International Variation in Accounting Measurement Rules and Analysts' Earnings Forecast Errors, Journal of Business Finance and Accounting 25(9-10): 1207-1247.

Beckers, S., Steliaros, M. and Thomson, A. (2004). Bias in European analysts' earnings forecasts, Financial Analysts Journal 60(2): 74-85.

Bolliger, G. (2004). The characteristics of individual analysts' forecasts in Europe, Journal of Banking and Finance 28(9): 2283-2309.

Bowen, R. M., Davis, A. K. and Matsumoto, D. A. (2002). Do Conference Calls Affect Analysts' Forecasts?, The Accounting Review 77(2): 285-316.

Bradshaw, M. T. (2009). Analyst Information Processing, Financial Regulation, and Academic Research, The Accounting Review 84(4): 1073-1083. 
Bradshaw, M. T. (2011). Analysts' Forecasts: What Do We Know After Decades of Work? Working Paper, Boston College.

Brown, L. D. (1997). Analyst forecasting errors: Additional evidence, Financial Analysts Journal 53(6): 81-88.

Brown, L. D. (2001). How Important Is Past Analyst Forecast Accuracy?, Financial Analysts Journal 57(6): 44-49.

Bushee, B. J., Matsumoto, D. A. and Miller, G. S. (2003). Open versus Closed Conference Calls: The Determinants and Effects of Broadening Access to Disclosure, Journal of Accounting and Economics 34(1-3): 149-180.

Bushee, B. J., Matsumoto, D. A. and Miller, G. S. (2004). Managerial and Investor Responses to Disclosure Regulation: The Case of Reg FD and Conference Calls, The Accounting Review 79(3): 617-643.

Byard, D. and Shaw, K. W. (2003). Corporate Disclosure Quality and Properties of Analysts' Information Environment, Journal of Accounting, Auditing and Finance 18(3): $355-378$.

Capstaff, J., Paudyal, K. and Rees, W. (1998). Analysts' Forecasts of German Firms' Earnings: a Comparative Analysis, Journal of International Financial Management and Accounting 9(2): 83-116.

Capstaff, J., Paudyal, K. and Rees, W. (2001). A Comparative Analysis of Earnings Forecasts in Europe, Journal of Business Finance and Accounting 28(5-6): 531-562.

Chang, J. J., Khanna, T. and Palepu, K. G. (2000). Analyst Activity Around the World. Working Paper, University of Pennsylvania and Harvard University.

Christensen, H. B., Hail, L. and Leuz, C. (2011). Capital-Market Effects of Securities Regulation: The Role of Implementation and Enforcement. Working Paper, University of Chicago.

Clement, M. B., Rees, L. and Swanson, E. P. (2003). The Influence of Culture and Corporate Governance on the Characteristics That Distinguish Superior Analysts, Journal of Accounting, Auditing and Finance 18(4): 593-618. 
Daske, H. and Wiesenbach, K. (2005). Praktische Probleme der zukunftsorientierten Schätzung von Eigenkapitalkosten am deutschen Kapitalmarkt, Finanz-Betrieb 7(6): 407-419.

Easton, P. (2009). Estimating the Cost of Capital Implied by Market Prices and Accounting Data, Foundations and Trends in Accounting 2(4): 241-364.

Frankel, R., Johnson, M. and Skinner, D. J. (1999). An Empirical Examination of Conference Calls as a Voluntary Disclosure Medium, Journal of Accounting Research 37(1): 133-150.

Glaum, M., Baetge, J., Grothe, A. and Oberdörster, T. (2011). Introduction of International Accounting Standards, Disclosure Quality and Accuracy of Analysts' Earnings Forecasts, European Accounting Review Forthcoming.

Hail, L. (2002). The Impact of Voluntary Corporate Disclosures on the Ex-Ante Cost of Capital for Swiss Firms, European Accounting Review 11(4): 741-773.

Harris, M. and Raviv, A. (1993). Differences of Opinion Make a Horse Race, Review of Financial Studies 6(3): 473-506.

Hollander, S., Pronk, M. and Roelofsen, E. (2010). Does Silence Speak? An Empirical Analysis of Disclosure Choices during Conference Calls, Journal of Accounting Research 48(3): 531-563.

Hope, O.-K. (2003a). Accounting Policy Disclosures and Analysts' Forecasts, Contemporary Accounting Research 20(2): 295-321.

Hope, O.-K. (2003b). Disclosure Practices, Enforcement of Accounting Standards and Analysts' Forecast Accuracy: An International Study, Journal of Accounting Research 41(2): 235-272.

Hope, O.-K. (2004). Variations in the Financial Reporting Environment and Earnings Forecasting, Journal of International Financial Management and Accounting 15(1): 2143.

Irani, A. J. (2004). The Effect of Regulation Fair Disclosure on the Relevance of Conference Calls to Financial Analysts, Review of Quantitative Finance and Accounting 22(1): 1528. 
Jegadeesh, N. and Kim, W. (2006). Value of analyst recommendations: International evidence, Journal of Financial Markets 9(3): 274-309.

Kim, O. and Verrecchia, R. E. (1991). Trading Volume and Price Reactions to Public Announcements, Journal of Accounting Research 29(2): 302-321.

Kim, O. and Verrecchia, R. E. (1994). Market liquidity and volume around earnings announcements, Journal of Accounting and Economics 17(1-2): 41-67.

Kim, O. and Verrecchia, R. E. (1997). Pre-announcement and event-period private information, Journal of Accounting and Economics 24(3): 395-419.

Lang, M. H. (1998). Discussion of "Bridging the Information Gap: Quarterly Conference Calls as a Medium for Voluntary Disclosure", Review of Accounting Studies 3(1-2): 169 173.

Lang, M. H. and Lundholm, R. J. (1996). Corporate Disclosure Policy and Analyst Behavior, The Accounting Review 71(4): 467-492.

Leuz, C. and Verrecchia, R. E. (2000). The Economic Consequences of Increased Disclosure, Journal of Accounting Research 38(1): 91-124.

Leuz, C. and Wysocki, P. (2008). Economic Consequences of Financial Reporting and Disclosure Regulation: A Review and Suggestions for Future Research. Working Paper, University of Chicago.

Matsumoto, D. A., Pronk, M. and Roelofsen, E. (2011). What Makes Conference Calls Useful? The Information Content of Managers' Presentations and Analysts' Discussion Sessions, The Accounting Review 86(4): 1383-1414.

Mayew, W. J. (2008). Evidence of Management Discrimination Among Analysts during Earnings Conference Calls, Journal of Accounting Research 46(3): 627-659.

Mayew, W. J. and Venkatachalam, M. (2011). The Power of Voice: Managerial Affective States and Future Firm Performance, Journal of Finance Forthcoming.

Naujoks, M., Aretz, K., Kerl, A. G. and Walter, A. (2009). Do German security analysts herd?, Financial Markets and Portfolio Management 23(1): 3-29. 
Skinner, D. J. (2003). Should firms disclose everything to everybody? A discussion of "Open vs. closed conference calls: the determinants and effects of broadening access to disclosure", Journal of Accounting and Economics 34(1-3): 181-187.

Stickel, S. E. (1989). The timing of and incentives for annual earnings forecasts near interim earnings announcements, Journal of Accounting and Economics 11(2-3): 275-292.

Verrecchia, R. E. (2001). Essays on disclosure, Journal of Accounting and Economics 32(1-3): $97-180$.

Zitzewitz, E. (2002). Regulation Fair Disclosure and the Private Information of Analysts. Working Paper, Stanford University. 
Figures and Tables 


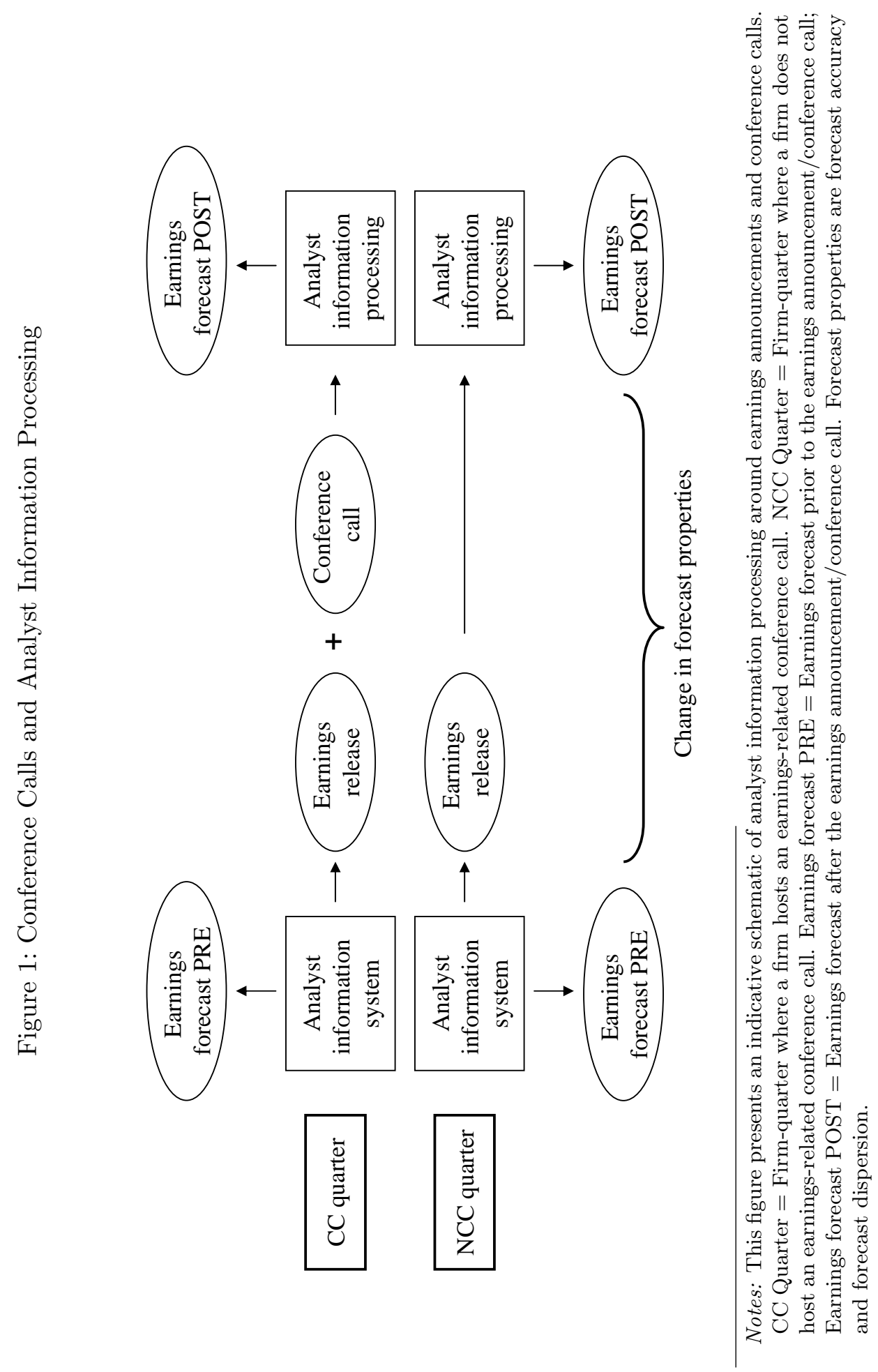




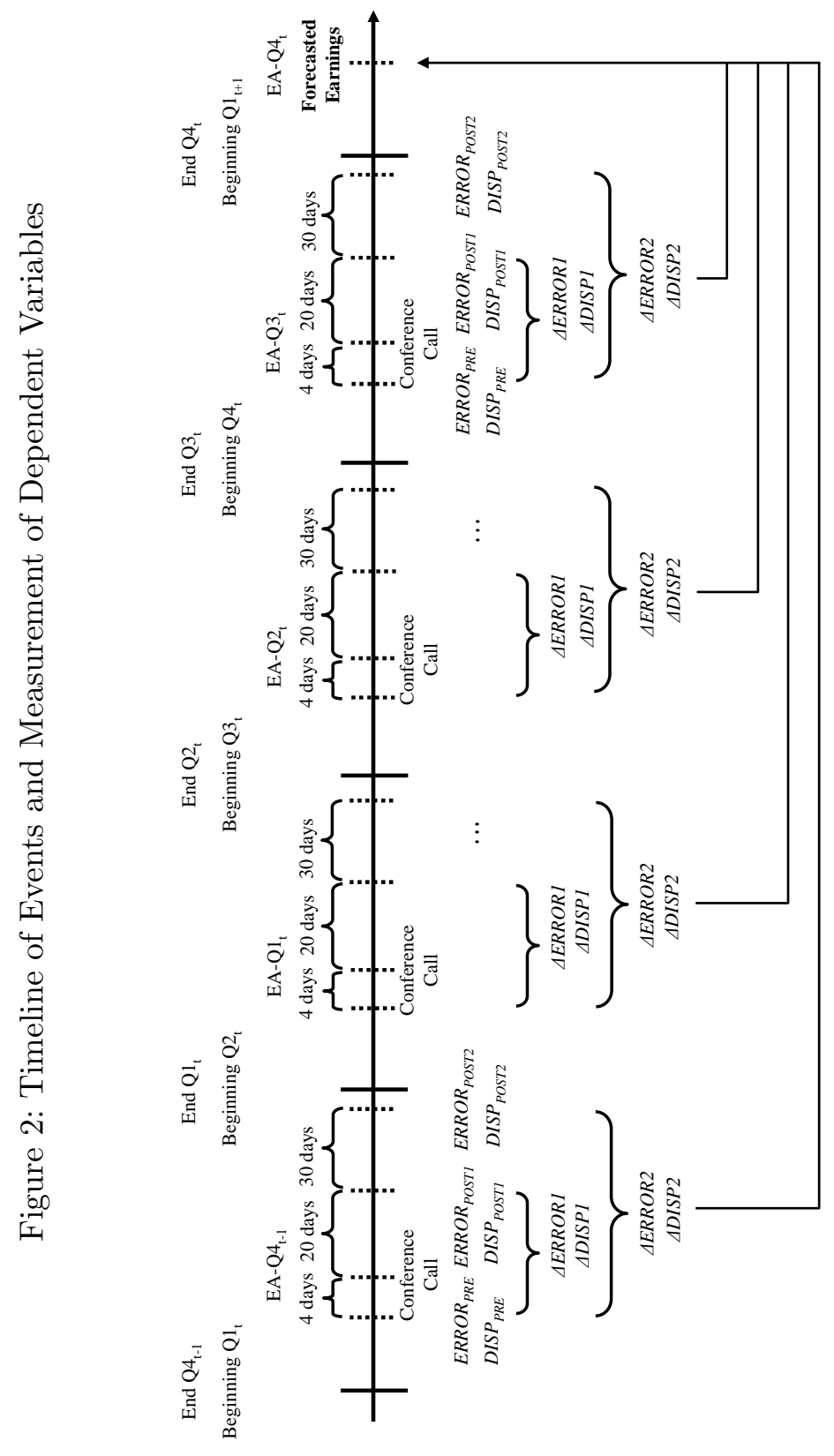

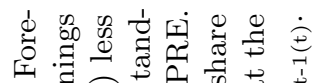

III

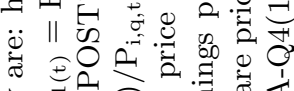

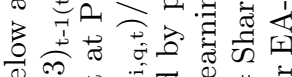

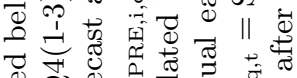

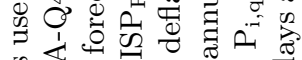

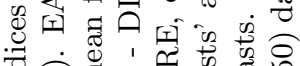

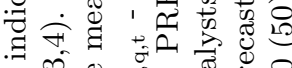

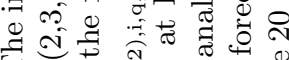

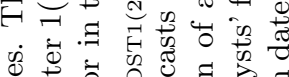

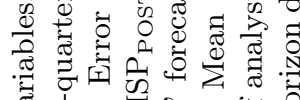
गै ㅂ.

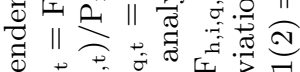

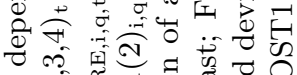
$\exists$ di

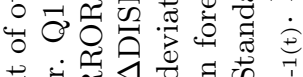

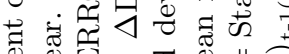

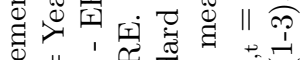
¿ II

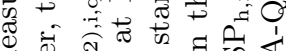
घ

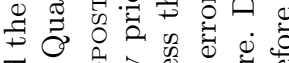

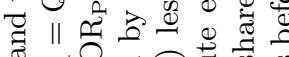
垈

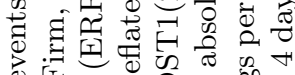
屯 I

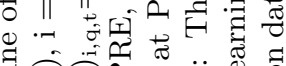

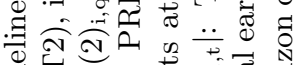

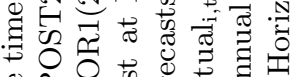

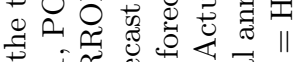

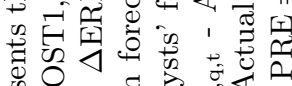
员

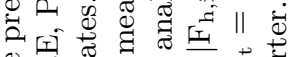
空窇

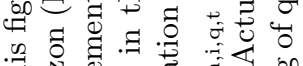
光.

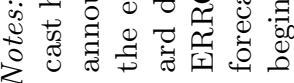


Figure 3: Revisions in Individual Forecasts - Conference Call Quarters vs.

Non-Conference Call Quarters

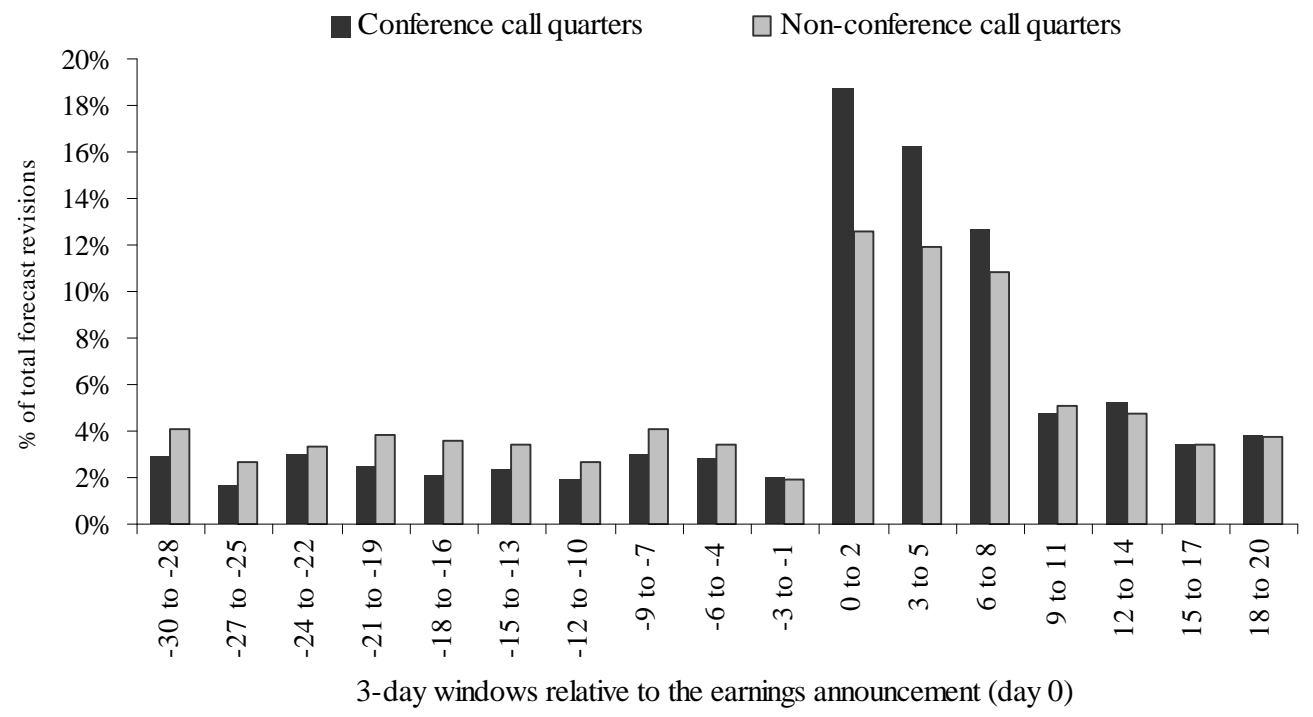

Notes: This figure shows revisions in individual forecasts during 3-day windows relative to an earnings announcement (day 0) as percentage of total individual forecast revisions during the window $[-30 ;+20]$ for conference call quarters and non-conference call quarters separately. Individual forecast revisions are computed as percentage of total individual forecast revisions occurring in a 90-day window $[-69 ;+20]$ around an earnings announcement $(\mathrm{N}=17,431)$. 


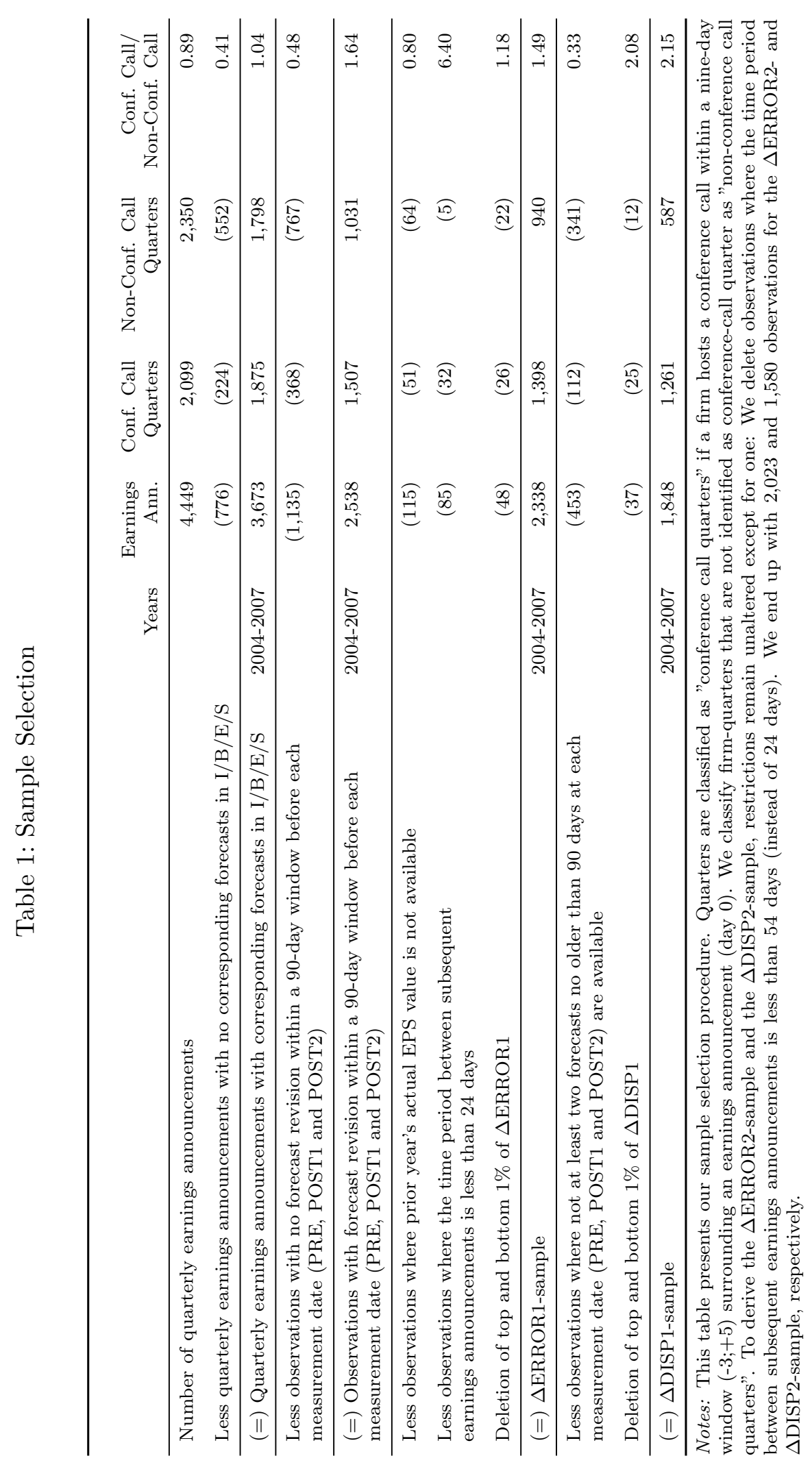


Table 2: Descriptive Statistics for Dependent, Explanatory and Control Variables

\begin{tabular}{|c|c|c|c|c|c|c|c|c|}
\hline Variables & $\mathrm{N}$ & Mean & Median & Minimum & Maximum & $\begin{array}{c}\text { Lower } \\
\text { Quartile }\end{array}$ & $\begin{array}{c}\text { Upper } \\
\text { Quartile }\end{array}$ & $\begin{array}{l}\text { Standard } \\
\text { Deviation }\end{array}$ \\
\hline \multicolumn{9}{|l|}{ Dependent Variables } \\
\hline$\Delta$ ERROR1 & 2,338 & $-0.00271 * * *$ & $-0.00042 * * *$ & -0.08358 & 0.02213 & -0.00345 & 0.00015 & 0.00908 \\
\hline$\Delta$ ERROR2 & 2,023 & $-0.00398 * * *$ & $-0.00079 * * *$ & -0.11631 & 0.03233 & -0.00470 & 0.00028 & 0.01298 \\
\hline$\Delta$ DISP1 & 1,848 & 0.00009 & 0.00000 & -0.01911 & 0.03764 & -0.00108 & 0.00085 & 0.00471 \\
\hline$\Delta$ DISP2 & 1,580 & 0.00010 & -0.00008 & -0.01865 & 0.03866 & -0.00140 & 0.00103 & 0.00511 \\
\hline \multicolumn{9}{|l|}{ Explanatory Variables } \\
\hline CC ( $\Delta$ ERROR1-sample) & 2,338 & 0.59795 & 1 & 0 & 1 & 0 & 1 & 0.49042 \\
\hline CC ( $\Delta$ DISP1-sample) & 1,848 & 0.68236 & 1 & 0 & 1 & 0 & 1 & 0.46568 \\
\hline \multicolumn{9}{|l|}{ Control Variables } \\
\hline SIZE (in EURbn) & 2,338 & 0.74299 & 0.56585 & 0.00651 & 94.97194 & 0.15802 & 3.45323 & 0.00802 \\
\hline SURP & 2,338 & 0.07857 & 0.02531 & 0.00000 & 14.81250 & 0.01116 & 0.05692 & 0.38814 \\
\hline$\Delta$ AGE1 & 2,338 & -11.05073 & -9.00000 & -84.00000 & 24.00000 & -28.00000 & 9.83333 & 25.67214 \\
\hline$\triangle \mathrm{AGE} 2$ & 2,023 & 8.59712 & 8.00000 & -84.00000 & 54.00000 & -9.00000 & 27.60000 & 26.53759 \\
\hline $\mathrm{ERROR}_{\mathrm{PRE}}$ & 2,338 & 0.04369 & 0.01224 & 0.00000 & 5.93149 & 0.00443 & 0.03050 & 0.17798 \\
\hline DISP $_{\text {PRE }}$ & 1,848 & 0.01129 & 0.00611 & 0.00000 & 0.56440 & 0.00315 & 0.01163 & 0.02315 \\
\hline NO & 2,338 & 7.39478 & 5.00000 & 1.00000 & 40.00000 & 2.00000 & 11.00000 & 7.05145 \\
\hline
\end{tabular}

Notes: This table presents descriptive statistics for the dependent, explanatory and control variables. For the definition of dependent variables, see Figure 2. The indices used below are: $\mathrm{i}=$ Firm, $\mathrm{q}=$ Quarter, $\mathrm{t}=$ Year. $\mathrm{CC}_{\mathrm{i}, \mathrm{q}, \mathrm{t}}=$ Dummy variable taking the value 1 if a quarter is a conference call quarter, and 0 otherwise. SIZE $\mathrm{E}_{\mathrm{i}, \mathrm{q}, \mathrm{t}}=$ Market value of equity at the beginning of quarter (for our empirical tests we use the log of the market value). $\mathrm{SURP}_{\mathrm{i}, \mathrm{t}}=\left(\left|\mathrm{EPS}_{\mathrm{i}, \mathrm{t}}-\mathrm{EPS}_{\mathrm{i}, \mathrm{t}-1}\right|\right) / \mathrm{P}_{\mathrm{i}, \mathrm{t}-1}$ : Absolute value of the earnings per share for the current fiscal year less the earnings per share for the prior fiscal year, deflated by the share price at the end of the prior fiscal year. $\triangle \mathrm{AGE} 1_{\mathrm{i}, \mathrm{q}, \mathrm{t}}=$ Average age of analysts' forecasts measured at POST1 less the average age of analysts' forecasts measured at PRE. $\triangle \mathrm{AGE} 2_{\mathrm{i}, \mathrm{q}, \mathrm{t}}=$ Average age of analysts' forecasts measured at POST2 less the average age of analysts' forecasts measured at PRE. ERROR $\mathrm{PRE}, \mathrm{i}, \mathrm{q}, \mathrm{t}_{\mathrm{T}}=$ Error in the mean forecast measured at PRE, deflated by the share price at PRE. DISP $P_{\mathrm{PRE}, \mathrm{i}, \mathrm{q}, \mathrm{t}}=$ Forecast dispersion measured at PRE, deflated by the share price at PRE. $\mathrm{NO}_{\mathrm{i}, \mathrm{q}, \mathrm{t}}=\mathrm{Number}$ of analysts following with forecasts no older than 90 days at PRE, POST1 and POST2. Market data are from Datastream. Control variables shown are based on the $\triangle$ ERROR1-sample except for $\triangle$ AGE2 and DISP $P_{P R E}$. For the dependent variables mean (median) differences from zero are tested by applying one sample mean t-tests (Wilcoxon signed-rank tests): ${ }^{*} p<0.1$, ** $p<0.05,{ }^{* * *} p<0.01$. 


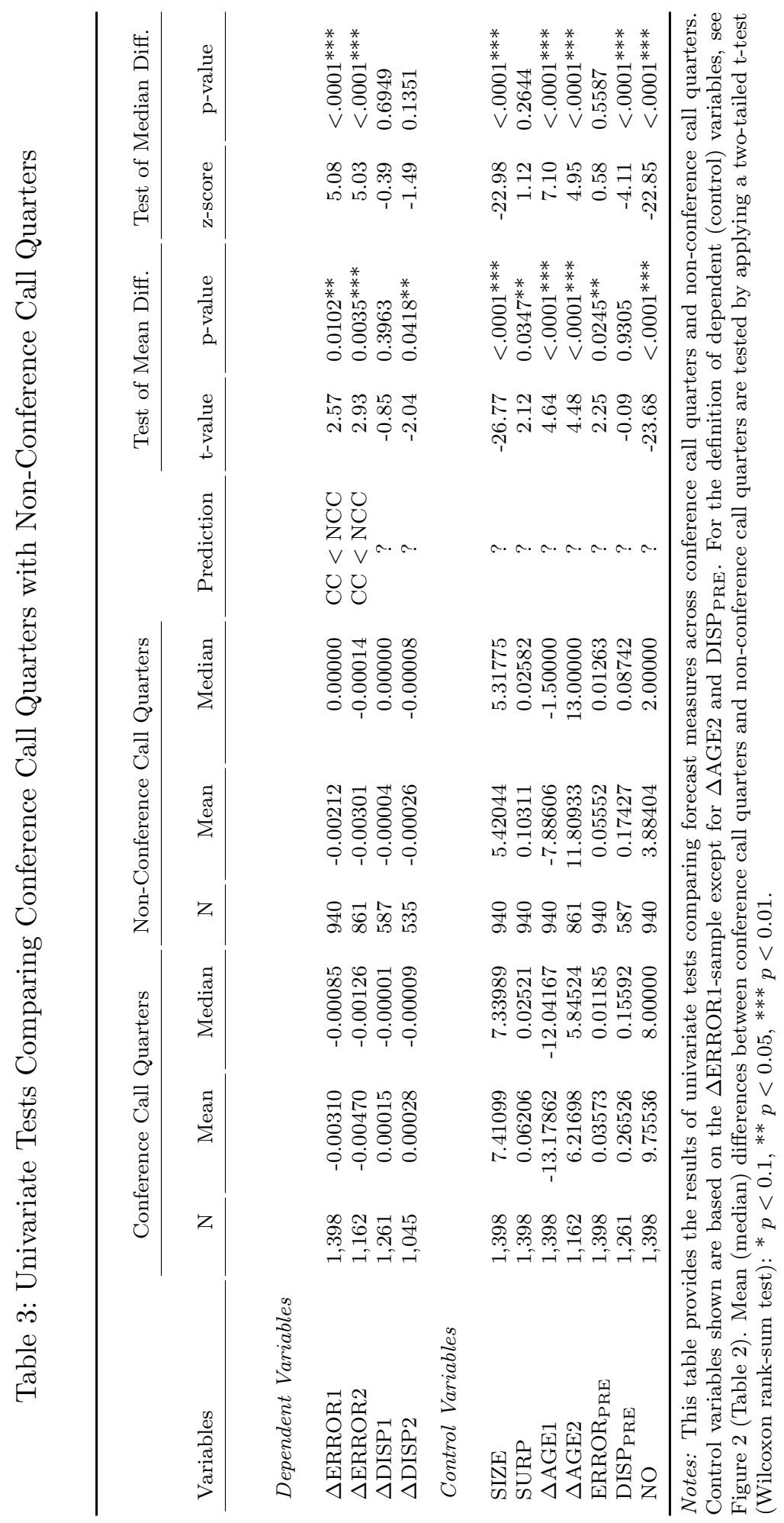




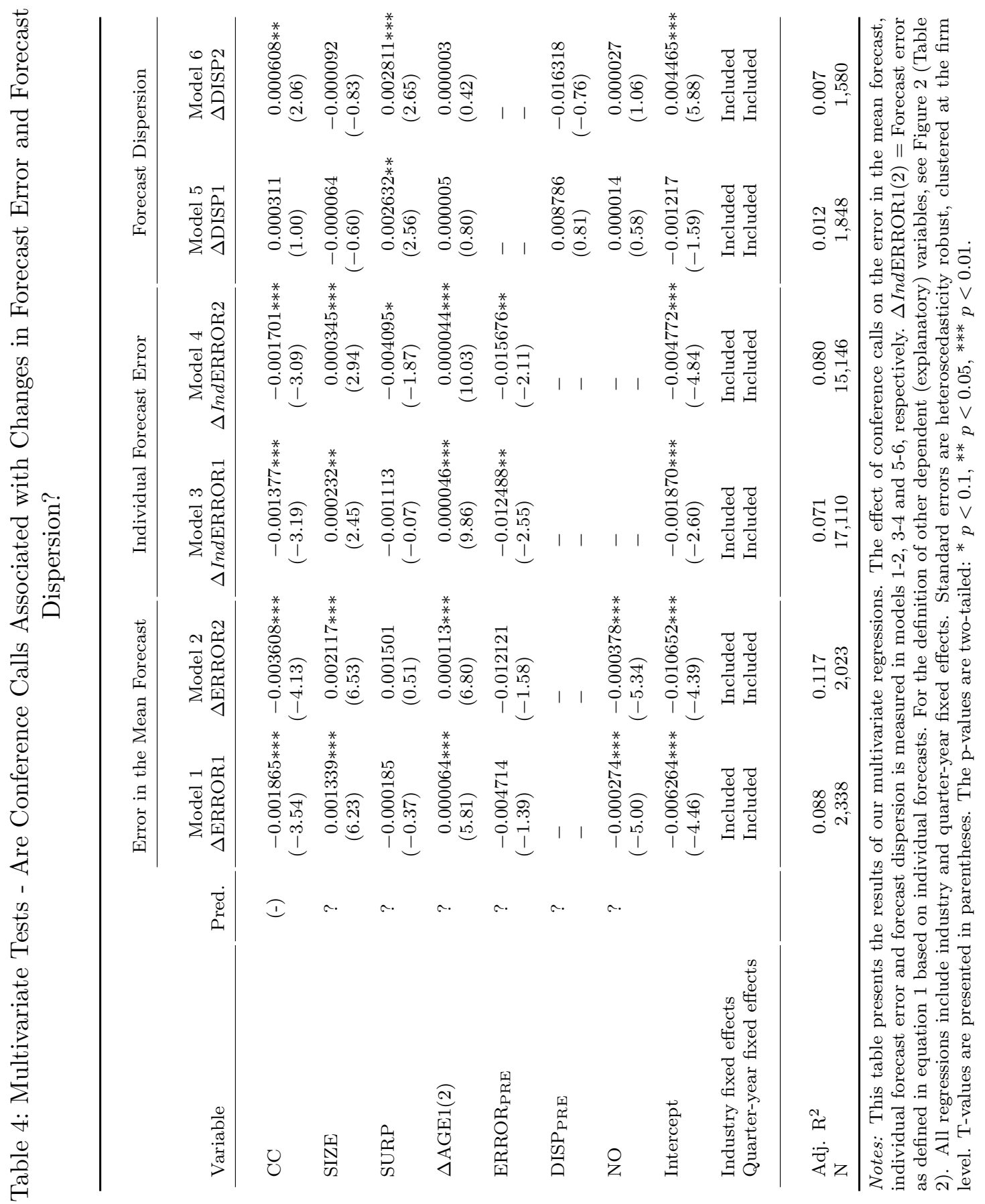




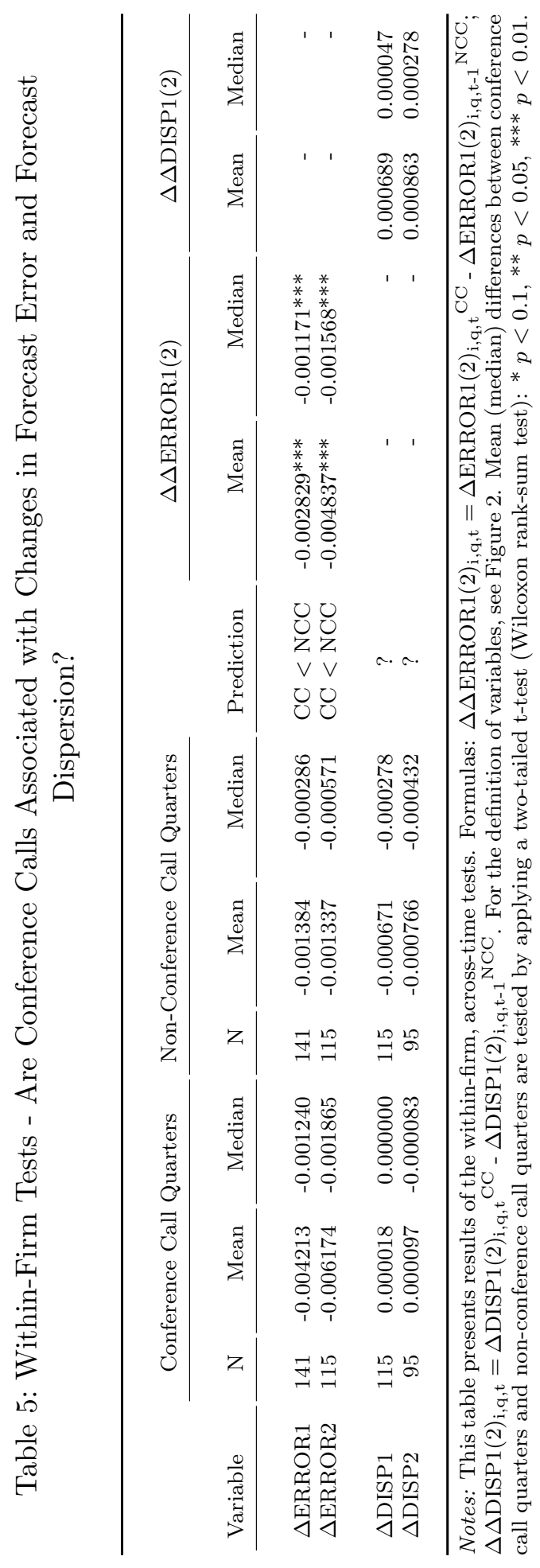


Table 6: Empirical Proxies for Uncertainty and Information Asymmetry before and after Conference Calls

\begin{tabular}{|c|c|c|c|c|c|c|c|c|}
\hline \multirow[b]{2}{*}{ CC Date } & \multirow[b]{2}{*}{$\begin{array}{r}\text { Horizon } \\
\text { Date }\end{array}$} & \multirow[b]{2}{*}{$\mathrm{N}$} & \multicolumn{3}{|c|}{ Uncertainty (V) } & \multicolumn{3}{|c|}{ Information Asymmetry $(1-\rho)$} \\
\hline & & & Median & $\begin{array}{l}\text { Sign Test } \\
\text { p-value }\end{array}$ & $\begin{array}{l}\text { Wilcoxon } \\
\text { p-value }\end{array}$ & Median & $\begin{array}{l}\text { Sign Test } \\
\text { p-value }\end{array}$ & $\begin{array}{l}\text { Wilcoxon } \\
\text { p-value }\end{array}$ \\
\hline \multirow[t]{2}{*}{$\mathrm{CC} * \mathrm{EA}-\mathrm{Q} 4_{\mathrm{t}-1}$} & PRE & 282 & 0.2812828 & & & 0.1173847 & & \\
\hline & POST1 & 282 & 0.2531633 & $<0.0001^{* * *}$ & $<0.0001^{* * *}$ & 0.1376249 & $0.0194^{* *}$ & $0.0271^{* *}$ \\
\hline \multirow{2}{*}{$\mathrm{CC} * \mathrm{EA}-\mathrm{Q} 1_{\mathrm{t}}$} & PRE & 245 & 0.2752158 & & & 0.1875925 & & \\
\hline & POST1 & 245 & 0.2336455 & $<0.0001^{* * *}$ & $<0.0001^{* * *}$ & 0.1933602 & $0.0652^{*}$ & $0.0500^{* *}$ \\
\hline \multirow[t]{2}{*}{$\mathrm{CC}^{*} \mathrm{EA}-\mathrm{Q} 2 \mathrm{t}$} & PRE & 235 & 0.2252174 & & & 0.1561987 & & \\
\hline & POST1 & 235 & 0.1863708 & $<0.0001^{* * *}$ & $<0.0001^{* * *}$ & 0.1864827 & $0.0006^{* * *}$ & $<0.0001^{* * *}$ \\
\hline \multirow[t]{2}{*}{ CC*EA-Q3 ${ }_{t}$} & PRE & 214 & 0.1483958 & & & 0.2815853 & & \\
\hline & POST1 & 214 & 0.1207090 & $<0.0001^{* * *}$ & $<0.0001^{* * *}$ & 0.3580590 & $0.0002^{* * *}$ & $<0.0001^{* * *}$ \\
\hline
\end{tabular}

Notes: This table presents empirical proxies developed by BKLS for analysts' overall uncertainty and information asymmetry among analysts both before and after conference calls. We also test for the sign of change in $\mathrm{V}$ and and (1$\rho$ ) between the PRE and POST1 horizon. CC*EA-Q4 $(1-3)_{\mathrm{t}-1(\mathrm{t})}=$ Earnings announcement in conference call quarters. PRE $=$ Horizon date 4 days before CC*EA-Q4(1-3) $)_{t-1(t)}$. POST1 $=$ Horizon date 20 days after CC*EA-Q4(1-3) $)_{-1(t)}$. $\mathrm{V}=$ Overall uncertainty (see equation 7$) ;(1-\rho)=$ Information asymmetry (see equation 8 ). Median differences from zero are tested by applying sign tests and Wilcoxon signed-rank tests: ${ }^{*} p<0.1,{ }^{* *} p<0.05,{ }^{* * *} p<0.01$. 


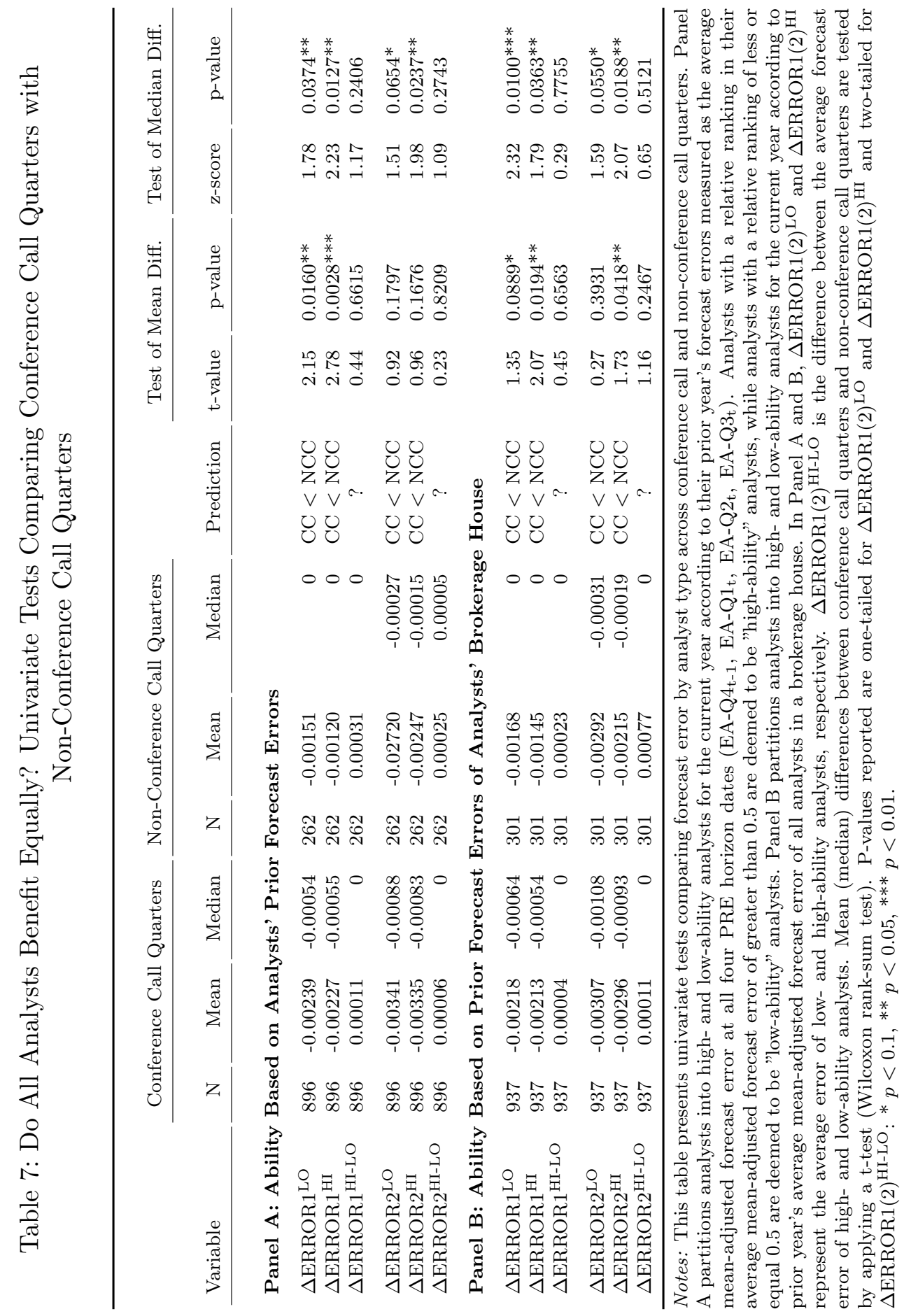

